\title{
When Linda meets Preeti: The Validation of Behavioral Biases in India
}

\author{
Nicholas Owsley, $\quad$ Aditya Laumas ${ }^{\dagger}$
}

August 27, 2021

\begin{abstract}
This paper presents results from an experiment testing 10 of the core biases from the behavioral economics literature amongst two distinct 'non-WEIRD' (Western Educated Industrialized Rich and Democratic) population groups: low-income Indians, and university students from an elite Indian university. The study tests for both the existence of the 'behavioral bias' for each measure with our 'non-WEIRD' sample and tests for heterogeneity across the socioeconomically distinct sub-samples. We find that both sub-samples display significant 'bias' in the majority of tests and across different categories of bias, suggesting that behavioral biases are not peculiar to Western samples. We further find that the patterns of bias are the same for each sub-sample for most measures, but that there are notable exceptions for a small subset of measures. In most of these cases, the student sample, closer to typical samples for this type of research, shows stronger bias than the low-income sample ${ }^{1}$.
\end{abstract}

*Busara Center for Behavioral Economics, Nairobi, Kenya, nicholas.owsley@busaracenter.org; orcid: 0000-0001-7898-6947

${ }^{\dagger}$ Centre for Social and Behaviour Change, Ashoka University, India

${ }^{1}$ This research was funded by the Centre for Social and Behaviour Change at Ashoka University. The authors would like to acknowledge Sami Horn's and Pooja Haldea's meaningful contributions to the research design. 


\section{Introduction}

Most research subjects in behavioral economics are culturally and socioeconomically homogeneous (Henrich et al., 2010b). Western populations account for $96 \%$ of research subjects in top psychology journal publications (Arnett, 2016) and the bulk of subjects in foundational behavioral economics research (Thaler, 2018; Kahneman, 2011). Even within this peculiar group, the significant majority of respondents are university students, and even more specifically, psychology and economics undergraduates. While this sampling bias does not pose a challenge to the internal validity of individual effects, the accumulation of these findings has produced a skewed body of evidence that is far too often taken as universal and which provides the basis for decision-making models and the direction of future research in the field (Fehr and Fischbacher, 2002; Cohen et al., 2020; Thaler, 2018; Camerer et al., 2016). This is particularly problematic given that numerous studies find considerable heterogeneity in decision patterns across different populations (Henrich et al., 2010b,c; Na et al., 2010; Barrett et al., 2016). Social preferences, risk preferences, and several other areas of decision-making appear to differ sharply across different geographies and socio-economic groups (Falk et al., 2018; Henrich et al., 2010a), and there is some evidence that more fundamental differences in cognition might exist (Nisbett et al., 2001; Tomasello et al., 2005). This highlights a potential risk that behavioral biases described in the behavioral economics literature are a function of Western sampling bias and their application in different contexts might not be appropriate.

Recent attempts to replicate core behavioral findings and expand subject pools to less typical samples represent an important shift in the field, but do not fully address the above problems. Most remain biased to Western samples, and efforts to sample from non-Western populations are typically concentrated amongst elite university students (McShane et al., 2019; Klein et al., 2018; Camerer et al., 2016). Further, many studies rely heavily on measures constructed and validated with Western samples, that in some cases fail tests of reliability and validity when used with non-WEIRD groups (Falk et al., 2018; Laajaj et al., 2019) - using uncontextualized versions of these measures could lead to considerable measurement error and the failure to identify true effects amongst new populations. Finally, most of these studies are not designed to identify heterogeneity in effects (McShane et al., 2019). There is thus considerable space to expand the evidence for behavioral biases amongst non-Western and non-typical samples.

This study presents the results of a randomized controlled trial in an experimental laboratory to test core behavioral economics measures with samples drawn from two non-Western populations of interest 457 low-income Indians in Haryana state (typical targets of behavioral development interventions), and 457 students from an elite Indian University based in the same state (more similar to typical Western samples and the target of newer studies expanding to non-WEIRD regions). We solicit responses for each of 10 behavioral biases through 11 individual survey-based measures modeled on original measures. Given several original measures were intuitively and empirically inappropriate for these groups, we adapted them through a structured contextualization process - this included working with local behavioral experts, prototyping, and piloting. Pilot and qualitative data show that without this contextualization, these instruments would likely generate considerable measurement error. We randomly assign treatment for each of our final measures, stratified by location, and randomly assign the order of measures. Finally, we specifically test both for the existence of the behavioral bias associated with each measure (as in the Western literature) and for the presence of effect heterogeneity between these distinct sub-samples. 
The majority of the measures generated significant effects, indicating the presence of 'behavioral biases' in our 'non-WEIRD' sample: 9 of the 11 tests showed a highly significant effect for the pooled sample. For most measures, the effects were not statistically different between our sub-samples, suggesting lowincome and elite student populations show roughly similar levels of bias for these measures. However, the student population alone showed the presence of "mental accounting" (Thaler, 1985), and showed marginally higher rates of bias for the "common ratio effect" (Kahneman and Tversky, 1979). The lowincome group showed a marginally higher rate of bias for the cognitive reflection test (Frederick, 2005), a largely unsurprising result.

The results from this study show that many of the core findings from behavioral economics are robustly observed across two highly distinct non-WEIRD populations - this gives cause for hope in the replicability of these and similar findings across geographic and socio-economic contexts. Nonetheless, given the heterogeneity in certain outcomes, and that some of these measures are foundational for models of decision making and many development interventions, it remains important to continue to gather evidence across diverse populations. The results also show that, when doing such work, researchers and practitioners should adapt their measures and materials if they intend to gather valid evidence from diverse target populations.

This study adds to the behavioral economics literature by testing core measures with non-typical samples, providing replication evidence for 9 behavioral biases and building the body of behavioral economics evidence coming from the Global South. Furthermore, this study provides details on a process for contextualizing measures which shows considerable promise for generating more valid data in non-WEIRD contexts. Finally, this study tests specifically for heterogeneity in effects between national sub-populations of scientific and policy interest and finds evidence supporting the application of behavioral models across both groups.

\section{Study design}

\subsection{Sample}

The sample for this study consists of two groups of respondents, for a full sample of 904:

- A sample of 457 low-income individuals from peri-urban/semi-rural villages in the vicinity of Sonepat, Haryana, India.

- A sample of 457 students from an elite liberal arts university in Haryana, India.

The motivation for selecting these distinct sub-groups is three-fold: i) we sought a population from a country in the global south in order to determine if core biases established through studies on Western samples are observed in populations in the global south, ii) we sought highly heterogeneous groups within a global south country to determine if we could observe variation in biases across socio-cultural dimensions within a global south country, iii) we sought two highly relevant groups regarding the status of the behavioral economics literature: a group of elite university students, a population to which studies in this field are now turning to expand their reach to 'non-WEIRD' populations; a group of low-income Indians typically targeted by development interventions and field research, but which continue to be excluded 
from more theoretical decision lab studies (upon which much of the theoretical literature informing development programs is predicated).

To recruit the low-income sample, we travelled between villages in semi-rural Haryana. When arriving at a village, we first contacted the local village leadership and then actively sought participants in the focal public areas within each village, such as school creches, with the aid of village leadership. Respondents were only included if they had completed eight years of education and were above the age of 18 and below the age of 60.457 respondents from this pool completed the full experiment.

To recruit the university sample, participants were recruited from the student administration; the primary eligibility requirement was being a registered student at Ashoka. We excluded students who were in a psychology program to avoid the confounds from exposure to similar materials, and included a question and control for whether or not students had taken any behavioral economics or psychology course. 457 respondents from this pool completed the full experiment.

The study is powered to detect an MDES of approximately 0.2 standard deviations for within-sub-sample treatment effects, and 0.41 for between-sub-sample differences in treatment effect (described below in the Econometric strategy).

\section{$2.2 \quad$ Procedures and Tasks}

\subsubsection{Task Selection}

The tasks were selected to cover a range of the most well-known and influential biases in the behavioral economics literature. In each case, we derived our final measures from original or commonly used versions of the measure to better compare to the findings with Western samples. In some cases, we underwent a rigorous iterative contextualization process to make measures culturally appropriate and preserve their ability to identify underlying biases. We finally selected 11 measures to identify 10 different biases that we 'grouped' according to "judgements and reasoning" and "economic preferences and decisions". The full list of measures is described below, with details of each measure in the appendix.

\section{Judgements and Reasoning:}

(a) Representativeness Heuristic - whether errors in probability assessment are made when respondents can make assessments according to 'representativeness'.

(b) Cognitive Reflection Test - A test of the capacity for reflective thinking over wrong intuitive responses.

(c) Mood Heuristic - whether a question to manipulate 'mood' affects general well-being assessments.

(d) Anchoring - whether assessments of a price are biased towards arbitrary numerical primes that can serve as 'anchors'.

(e) Loss Framing - A test for differences in choices in a gamble depending on question framing for identical scenarios. 
(f) Default - Assessment - whether a default selection for an assessment affects the selection.

\section{Economic Preferences and Decisions:}

(a) Present-bias - whether participants are more 'impatient' over choices that could yield benefits now vs in the future.

(b) Common Ratio Effect - whether participants have the same risk preference over different amounts.

(c) Decoy (Atrraction) Effect - whether an irrelevant 'decoy' option affects choice in a goods menu.

(d) Mental Accounting - whether different framing affects purchasing decisions.

(e) Defaults - Charity Contribution - whether a pre-selected default option affects decisions on which charity to contribute to.

\subsubsection{Task Contextualization}

Nine of the eleven tasks were closely drawn from the original or most common measures in the literature 2. Several of the these nine measures contained culturally-specific reference points that were potentially inaccessible for the Indian subject pools. In these cases, there was a high risk of measurement error in responses due to low comprehension of questions and choice sets. The measures therefore underwent a thorough review and multi-step contextualization process in order to preserve the core psychological test (see the appendix for originals and contextualized versions).

First, measures were reviewed for their contextual appropriateness for the target subject pools. Cases where concepts or references might appear 'alien' or inaccessible to the local target populations were flagged for contextualization. After determining the inappropriate reference points, the fundamental elements of each measure were identified. This imposed a clear structure for each measure that ensured that contextualized versions preserved the format and substance of originals. A team of India- and Kenyabased behavioral science researchers then either substituted local cultural references for foreign ones, or developed full local measures where the originals were not easily adapted, in each case preserving the format and features of the original.

To illustrate this process, the 'Linda Problem', the original measure of the 'Representativeness Heuristic', was flagged and redeveloped (see the appendix for both versions). The original measure relies on research subjects understanding culturally-embedded characteristics of a young woman's profile. Subjects should be cued that Linda is a certain 'type' of person that they are familiar with, and therefore should have somewhat predictable expectations of her likelihood of engaging in different occupations on an accompanying list. In this case, the reference points in the original are distinctly Western and somewhat outdated. The Indian target populations are therefore not likely to make reliable assessments since they are not familiar with 'Linda' or her possible occupations. The core elements of the measure that needed preservation were identified: i) a short profile of a recognizable 'type' of person in the Indian context (for

\footnotetext{
${ }^{2}$ the two exceptions were the two measures of 'default' effects which were straightforward applications of the principle of default selections in economic decisions
} 
comparability, preferably a socially engaged young woman); ii) a list of plausible occupations that could associate with that person; iii) variation in the likelihood of each occupation being undertaken; iv) two occupations on the list - one that is likely and one that is unlikely - that seem incongruous (but not an impossible combination). Within this structure, a profile for 'Preeti' and a list of occupations that an Indian woman 'of this type' could reasonably undertake were developed.

All contextualized measures, like the revised 'Preeti Problem' above, were then piloted with Indian field staff, to check for comprehension, cultural appropriateness, and response distributions. This included a combination of cognitive debriefing, prototyping, and pilot data collection. Measures were then be iterated following several rounds of this type of feedback. This process was repeated with respondents from the target subject pools, and measures were adapted and finalized accordingly. Ultimately, we finalized nine India-specific measures that preserved the features of the originals.

\subsection{Data Collection}

Data collection took place between July and September 2019 and was conducted in a decision lab for all respondents broken down into individual sessions. Each session included 20 respondents, who submitted responses to all tasks on individual Windows tablet computers on the oTree software. The script for the full session and each task was read allowed to the entire set of respondents present. Each respondent received INR 400 for their participation, provided in cash directly after the session.

Each of the 11 tasks were administered sequentially after a basic demographic survey. The order of each task was randomized.

\subsection{Treatment Assignment}

Since this study is interested in determining differences in effects between different populations, assign-

ment in these cases is obviously non-random. Specifically, assignment to 'student' and 'low-income' populations.

For the measures, 7 of the 11 tasks include treatment and control conditions - in these 7 cases, participants were randomly assigned with equal probability to each condition, and assignment occurred on the sessiontask level, such that individuals within the same session were randomly assigned to different conditions 'across tasks' but the same condition 'across individuals'. For each respective task, individuals within the same session are in the same treatment group (See the Appendix for details of treatment conditions for each task).

\section{Empirical Strategy}

We administered two types of tasks: one which simply measures a particular response, and one which estimates the effect of a treatment condition on a response. To analyze outcome variables which are simply mean responses, we use the following OLS model: 
Model 1 (No treatment condition):

$$
Y_{i}=\beta_{0}+\beta_{1} \text { Student }_{i}+\epsilon_{i}
$$

For outcomes where there is a treatment condition, we use the following models:

Model 2 (Treatment condition - raw effect):

$$
Y_{i}=\beta_{0}+\beta_{1} \text { Treatment }_{i}+\epsilon_{i}
$$

Model 3 (Treatment condition - interaction effect):

$$
Y_{i}=\beta_{0}+\beta_{1} \text { Student }_{i}+\beta_{2} \text { Treatment }_{i}+\beta_{3} \text { Student }_{i} * \text { Treatment }_{i}+\epsilon_{i}
$$

Where $Y_{i}$ is the outcome of interest for respondent $i$, Student $_{i}$ is a dummy variable equal to 1 if the respondent is a student, Treatment is a dummy variable equal to 1 if the respondent was randomly assigned to a treatment group, and Student $_{i} *$ Treatment $_{i}$ is the interaction term used to identify the differential effect of the treatment for students. $\beta_{1}$ in Equation 2 provides the raw treatment effect on the full sample. $\beta_{2}$ in Equation 3 provides the treatment effect for the low-income group alone, while $\beta_{3}$ in Equation 3 provides the differential treatment effect for students compared to the low-income sub-sample. For robustness checks, each of the above models is also estimated with a vector of control variables $X_{i}$ included in an additional specification.

These models apply to all measures with the exception of the Mood Heuristic, which follows a slightly different analytical procedure owing to the treatment effect being the product of an additional interaction 3

\section{Results}

\subsection{Overall Results}

The foremost summary of the results is that there is clear evidence of the existence of most of the tested biases in the pooled Indian sample - 9 out of the 11 measures show highly significant (at the $1 \%$ and in many cases at the $0.1 \%$ level) effects in the hypothesized direction (Table 1 ). The exceptions are the 'Mood Heuristic' and the Default selection for assessment.

Second, the patterns of bias are predominantly the same across both sub-samples. Effects are significant (at the 10\% level) in the expected direction for both sub-samples in 8 of the 11 measures. There is a significant difference in effect in only 3 of the 11 tests between students and the low-income sample, and in 2 of these cases the bias is more pronounced rather than not existing for one of the sub-samples.

Third, there are interesting differences in effects between sub-samples for 2 of the measures, which warrant further discussion, both of which are in the 'economic preferences and decisions' measures.

\footnotetext{
${ }^{3}$ This is described under the 'Mood Heuristic' in the appendix
} 
Table 1: Full Regression Results - All Measures

\begin{tabular}{|c|c|c|c|c|c|c|c|c|}
\hline \multirow[b]{2}{*}{ Judgements \& Reasoning } & \multicolumn{3}{|c|}{ Model without Controls } & \multicolumn{3}{|c|}{ Model with Controls } & \multirow[b]{2}{*}{$\begin{array}{l}\text { Significant } \\
\text { effect in } \\
\text { hypothesized } \\
\text { direction }\end{array}$} & \multirow[b]{2}{*}{$\begin{array}{l}\text { Significant } \\
\text { difference in } \\
\text { effect } \\
\text { between } \\
\text { sub-samples }\end{array}$} \\
\hline & Overall effect & $\begin{array}{l}\text { Low-income } \\
\text { only effect }\end{array}$ & $\begin{array}{l}\text { Difference } \\
\text { in effect } \\
\text { between } \\
\text { sub-samples }\end{array}$ & Overall effect & $\begin{array}{l}\text { Low-income } \\
\text { only Effect }\end{array}$ & $\begin{array}{c}\text { Difference } \\
\text { in effect } \\
\text { between } \\
\text { sub-samples }\end{array}$ & & \\
\hline Representativeness Heuristic & $\begin{array}{l}0.58^{* * *} \\
(35.42)\end{array}$ & $\begin{array}{l}0.58^{* * *} \\
(25.27)\end{array}$ & $\begin{array}{l}-0.01 \\
(-0.33)\end{array}$ & & & $\begin{array}{l}-0.02 \\
(-0.25)\end{array}$ & Yes & No \\
\hline Cognitive Reflection Task & $\begin{array}{l}0.25^{* * *} \\
(22.16)\end{array}$ & $\begin{array}{c}0.07^{* * *} \\
(5.52)\end{array}$ & $\begin{array}{l}0.32 * * * \\
(17.97)\end{array}$ & & & $\begin{array}{c}0.282^{* * *} \\
(7.54)\end{array}$ & Yes & Yes \\
\hline Mood Heuristic & $\begin{array}{l}-0.01 \\
(-0.48)\end{array}$ & $\begin{array}{l}-0.05 \\
(-1.43)\end{array}$ & 0.05 & $\begin{array}{l}-0.01 \\
(-0.71)\end{array}$ & $\begin{array}{l}-0.05 \\
(-1.40)\end{array}$ & 0.05 & No & No \\
\hline Anchoring & $\begin{array}{c}716.61^{* * *} \\
(13.33)\end{array}$ & $\begin{array}{c}720.07^{* * *} \\
(9.47)\end{array}$ & $\begin{array}{l}-1.06 \\
(-0.01)\end{array}$ & $\begin{array}{c}732.46^{* * *} \\
(13.63)\end{array}$ & $\begin{array}{c}720.07^{* * *} \\
(9.47)\end{array}$ & $\begin{array}{l}-25.6 \\
(-0.23)\end{array}$ & Yes & No \\
\hline Loss Framing & $\begin{array}{c}0.13^{* * * *} \\
(3.95)\end{array}$ & $\begin{array}{l}0.09^{*} \\
(1.95)\end{array}$ & $\begin{array}{c}0.08 \\
(1.23)\end{array}$ & $\begin{array}{c}0.14^{* * * *} \\
(4.19)\end{array}$ & $\begin{array}{l}0.09^{*} \\
(1.95)\end{array}$ & $\begin{array}{c}0.08 \\
(1.18)\end{array}$ & Yes & No \\
\hline Defaults - Assessment & $\begin{array}{c}-0.92^{* * *} \\
(-4.87)\end{array}$ & $\begin{array}{l}-0.32 \\
(-1.45)\end{array}$ & $\begin{array}{l}0.32 \\
(1.1)\end{array}$ & $\begin{array}{l}-0.15 \\
(-1.05)\end{array}$ & $\begin{array}{c}-0.3 \\
(-1.45)\end{array}$ & $\begin{array}{c}0.29 \\
(0.98)\end{array}$ & No & No \\
\hline \multicolumn{9}{|l|}{$\begin{array}{l}\text { Economic Preferences } \\
\text { \& Decisions }\end{array}$} \\
\hline Present Bias & $\begin{array}{l}0.40^{* * *} \\
(24.75)\end{array}$ & $\begin{array}{l}0.40^{* * *} \\
(17.53)\end{array}$ & $\begin{array}{l}-0.01 \\
(-0.06)\end{array}$ & & & $\begin{array}{c}0.01 \\
(0.11)\end{array}$ & Yes & No \\
\hline Common Ratio Effect & $\begin{array}{r}0.25^{* * *} \\
(17.51)\end{array}$ & $\begin{array}{c}0.14^{* * *} \\
(7.13)\end{array}$ & $\begin{array}{c}0.22^{* * *} \\
(8.03)\end{array}$ & & & $\begin{array}{c}0.17^{* * *} \\
-2.94\end{array}$ & Yes & Yes \\
\hline Decoy Effect & $\begin{array}{c}0.19^{* * *} \\
(6.63)\end{array}$ & $\begin{array}{c}0.21^{* * *} \\
(5.07)\end{array}$ & $\begin{array}{l}-0.01 \\
(-0.11)\end{array}$ & $\begin{array}{c}0.20^{* * *} \\
(7.11)\end{array}$ & $\begin{array}{c}0.21^{* * *} \\
(5.07)\end{array}$ & $\begin{array}{l}-0.02 \\
(-0.27)\end{array}$ & Yes & No \\
\hline Mental Accounting & $\begin{array}{c}-0.13^{* * *} \\
(-4.15)\end{array}$ & $\begin{array}{l}-0.03 \\
(-0.60)\end{array}$ & $\begin{array}{c}-0.21^{* * *} \\
(-3.22)\end{array}$ & $\begin{array}{c}-0.13^{* * *} \\
(-4.01)\end{array}$ & $\begin{array}{l}-0.03 \\
(-0.61)\end{array}$ & $\begin{array}{c}-0.22^{* * *} \\
(-3.36)\end{array}$ & Yes & Yes \\
\hline Defaults - Charity & $\begin{array}{c}0.08^{* * *} \\
(2.61)\end{array}$ & $\begin{array}{l}0.08^{*} \\
(1.74)\end{array}$ & $\begin{array}{c}-0.01 \\
(-0.04)\end{array}$ & $\begin{array}{c}0.08^{* *} \\
(2.56)\end{array}$ & $\begin{array}{c}0.08^{*} \\
1.74\end{array}$ & $\begin{array}{c}-0.01 \\
(-0.22)\end{array}$ & Yes & No \\
\hline
\end{tabular}

Table shows output for regressions on each of the 11 measures. T-statistics are in parentheses. ***, **, and * indicate significance at the 1,5 , and 10 percent critical level.

1) In this column, green highlighting denotes a significant effect. Red highlighting denotes no effect.

2) In this column, green highlighting denotes a predicted equivalence or difference, and red denotes a surprising or unpredicted equivalence or difference. In this case, only The CRT was predicted to be different.

In the "Overall Effect" column, the mean of the outcome compared to zero (or to 0.5 for the CST) and $\beta_{1}$ from Model 2 are reported for no treatment condition and treatment condition measures respectively.

In "Low Income Only Effect" the co-efficients $\beta_{0}$ in model 1 and $\beta_{2}$ in Model 3 are given for no treatment and treatment condition measures respectively. In "Difference in..." the co-efficients $\beta_{1}$ in Model 1 and $\beta_{3}$ in Model 3 are given for no treatment and treatment condition measures respectively.

The following sub-sections describe some of the more notable results from individual tests. However, they do not give a thorough account of each - full regression results for each measure can be seen in Tables 2 and 3 and graphs for each in the appendix. 
Figure 1: Mean responses on measures with no treatment condition by sub-sample

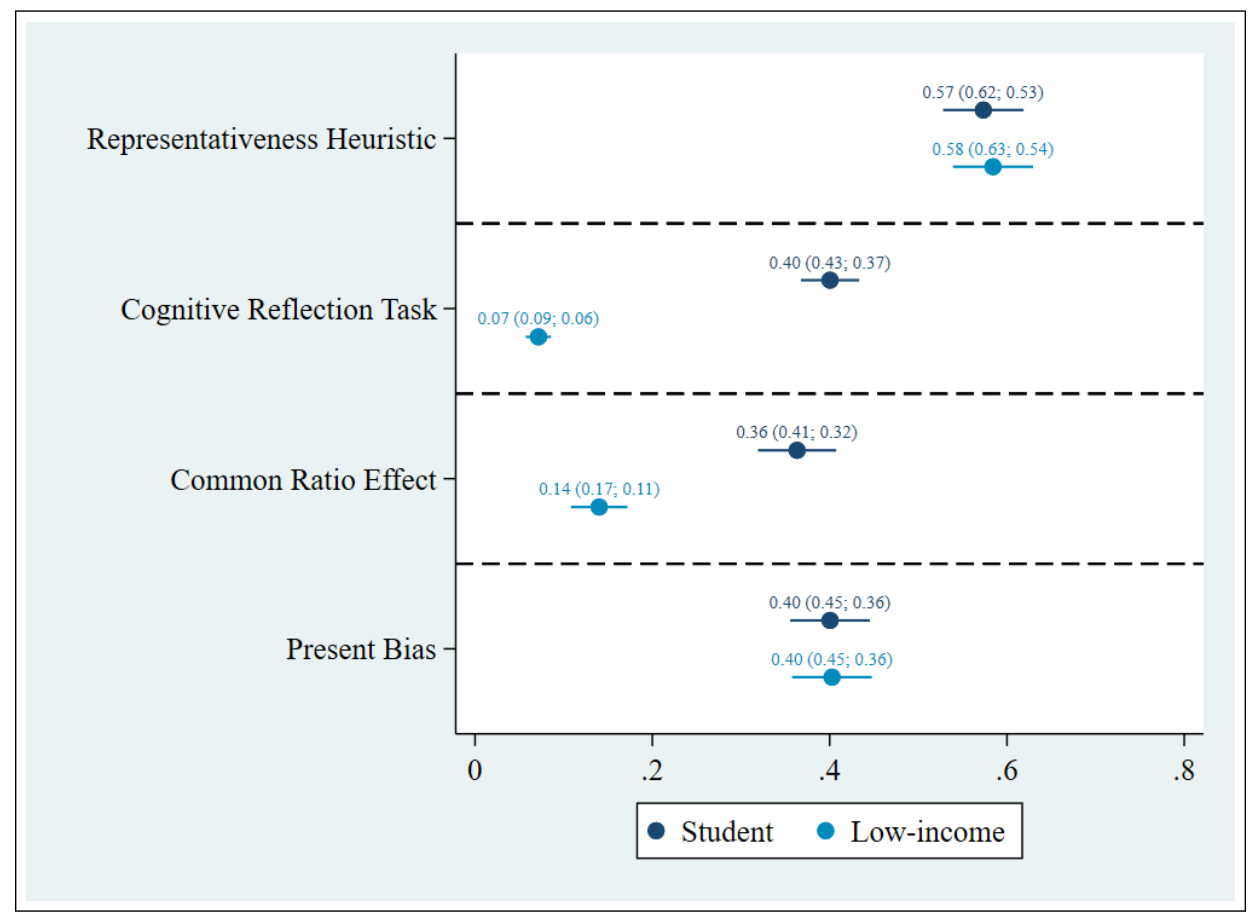

Note: points represent mean values by sub-sample for each measure. Lines represent $95 \%$ confidence intervals.

Figure 2: Mean responses on measures with treatment condition by treatment group and sub-sample

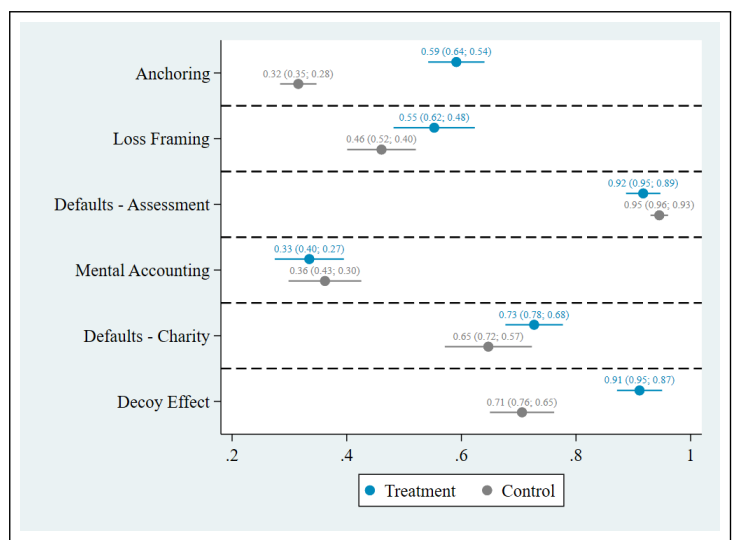

(a) Low-income

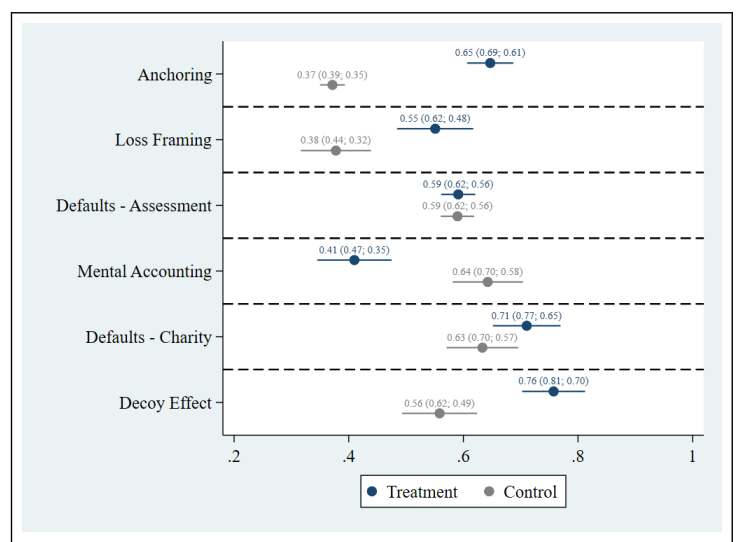

(b) Student

Note: points represent mean values by treatment group and sub-sample for each measure. Lines represent $95 \%$ confidence intervals. Sub-figure a) indicates these parameters for the low-income sub-sample and sub-figure b) for the student sample. The mood heuristic is omitted as it relies on correlations rather than pure means to determine the bias. 


\subsection{Judgements and Reasoning}

The measures grouped under 'judgements and reasoning' include several canonical Kahneman and Tversky question sets, such as the "Asian Disease Problem" (as a measure of Loss Aversion) and the "Linda Problem" (as a measure of the Representativeness Heuristic). In both cases, the measures were contextualized to become the "African Disease Problem" and the "Preeti Problem" respectively. For these, there was pronounced and statistically significant evidence of loss aversion and of wrongful application of the 'representativeness heuristic' in probability judgements. In the African Disease Problem, the low-income sample is 11pp more likely to choose the risky option under a loss frame than a gain frame for an identical choice (Figure 2), while the student sample is 15pp more likely. For the Preeti Problem, 58\% of the low-income sample and $57 \%$ of the student sample incorrectly ranked the description of the young woman "Preeti" of her being a "a garment retailer who volunteers for a local NGO" as more likely than her just being a garment retailer (which is probabilistically impossible and therefore considered a 'bias'; Figure 1). This grouping also includes the Cognitive Reflection Test - a test of whether or not participants engage reflective reasoning in lieu of making intuitive (but wrong) assessments. Both sub-samples get the relatively simple arithmetic problems systematically wrong by tending towards intuitive answers (for example, indicating that a ball costs 10 rupees instead of 5 in the classic Fredericks (2005) measure ${ }^{4}$ ). The mood heuristic measure, a test of whether or not a question to induce positive or negative mood effects different assessments of general well-being, did not have any effect on assessments.

Table 2: Regression Output for Biases Related to "Judgements and Reasoning"

\begin{tabular}{|c|c|c|c|c|c|c|c|c|c|c|}
\hline & \multirow{2}{*}{$\frac{\text { Representativeness }}{(1)}$} & \multirow{2}{*}{$\begin{array}{c}\text { CRT } \\
(2) \\
\end{array}$} & \multicolumn{2}{|c|}{ "Anchoring } & \multicolumn{2}{|c|}{ Loss Framing } & \multicolumn{2}{|c|}{ Default Assess } & \multicolumn{2}{|c|}{ Mood } \\
\hline & & & (3) & (4) & $(5)$ & $(6)$ & $(7)$ & $(8)$ & (9) & $(10)$ \\
\hline \multicolumn{11}{|c|}{ Without Controls } \\
\hline Differential Effect for Student & $\begin{array}{l}-0.01 \\
(0.03)\end{array}$ & $\begin{array}{c}0.33^{* * *} \\
(0.02)\end{array}$ & & $\begin{array}{c}-1.07 \\
(107.14)\end{array}$ & & $\begin{array}{c}0.08 \\
(0.07)\end{array}$ & & $\begin{array}{c}0.32 \\
(0.29)\end{array}$ & & $\begin{array}{c}0.05 \\
(0.04)\end{array}$ \\
\hline Treatment & & & $\begin{array}{c}716.62^{* * * *} \\
(53.72)\end{array}$ & $\begin{array}{c}720.08^{* * * *} \\
(75.97)\end{array}$ & $\begin{array}{c}0.13^{* * *} \\
(0.03)\end{array}$ & $\begin{array}{l}0.09^{*} \\
(0.05)\end{array}$ & $\begin{array}{c}-0.92^{* * *} \\
(0.19)\end{array}$ & $\begin{array}{l}-0.31 \\
(0.21)\end{array}$ & $\begin{array}{l}-0.01 \\
(0.02)\end{array}$ & $\begin{array}{l}-0.05 \\
(0.03)\end{array}$ \\
\hline Student Dummy & & & & $\begin{array}{c}146.44^{*} \\
(80.74)\end{array}$ & & $\begin{array}{c}-0.08^{*} \\
(0.04)\end{array}$ & & $\begin{array}{c}-3.91^{* * *} \\
(0.19)\end{array}$ & & \\
\hline Constant & $\begin{array}{c}0.58^{* * *} \\
(0.02)\end{array}$ & $\begin{array}{c}0.07^{* * *} \\
(0.01) \\
\end{array}$ & $\begin{array}{c}898.84^{* * *} \\
(40.48) \\
\end{array}$ & $\begin{array}{c}823.95^{* * *} \\
(57.74)\end{array}$ & $\begin{array}{c}0.42^{* * *} \\
(0.02)\end{array}$ & $\begin{array}{c}0.46^{* * *} \\
(0.03)\end{array}$ & $\begin{array}{c}8.81^{* * *} \\
(0.13)\end{array}$ & $\begin{array}{c}10.40^{* * *} \\
(0.12)\end{array}$ & $\begin{array}{c}8.18^{* * *} \\
(0.13)\end{array}$ & $\begin{array}{c}8.91^{* * * *} \\
(0.17)\end{array}$ \\
\hline Observations & 914 & 914 & 914 & 914 & 914 & 914 & 913 & 913 & 914 & 914 \\
\hline \multicolumn{11}{|c|}{ Including Controls } \\
\hline Differential Effect for Student & $\begin{array}{l}-0.02 \\
(0.07)\end{array}$ & $\begin{array}{c}0.28^{* * *} \\
(0.04)\end{array}$ & & $\begin{array}{c}-25.60 \\
(107.77)\end{array}$ & & $\begin{array}{c}0.08 \\
(0.07)\end{array}$ & & $\begin{array}{c}0.29 \\
(0.29)\end{array}$ & & $\begin{array}{c}0.05 \\
(0.04)\end{array}$ \\
\hline Treatment & & & $\begin{array}{c}732.47^{* * * *} \\
(53.74)\end{array}$ & $\begin{array}{c}745.30^{* * *} \\
(76.21)\end{array}$ & $\begin{array}{c}0.14^{* * *} \\
(0.03)\end{array}$ & $\begin{array}{c}0.10^{* *} \\
(0.05)\end{array}$ & $\begin{array}{l}-0.15 \\
(0.15)\end{array}$ & $\begin{array}{l}-0.30 \\
(0.21)\end{array}$ & $\begin{array}{l}-0.01 \\
(0.02)\end{array}$ & $\begin{array}{l}-0.05 \\
(0.03)\end{array}$ \\
\hline Student Dummy & & & $\begin{array}{c}95.80 \\
(109.11)\end{array}$ & $\begin{array}{c}110.65 \\
(125.81)\end{array}$ & $\begin{array}{l}-0.05 \\
(0.07)\end{array}$ & $\begin{array}{l}-0.09 \\
(0.08)\end{array}$ & $\begin{array}{c}-3.46^{* * *} \\
(0.29)\end{array}$ & $\begin{array}{c}-3.59^{* * *} \\
(0.33)\end{array}$ & & \\
\hline Constant & $\begin{array}{c}0.76^{* *} \\
(0.36)\end{array}$ & $\begin{array}{c}0.13 \\
(0.20)\end{array}$ & $\begin{array}{l}-410.09 \\
(590.57)\end{array}$ & $\begin{array}{l}-422.85 \\
(593.32)\end{array}$ & $\begin{array}{c}0.79^{* *} \\
(0.37)\end{array}$ & $\begin{array}{l}0.82^{* *} \\
(0.37)\end{array}$ & $\begin{array}{c}9.80^{* * * *} \\
(1.58)\end{array}$ & $\begin{array}{c}9.92^{* * *} \\
(1.58)\end{array}$ & $\begin{array}{c}8.56^{* * *} \\
(1.72)\end{array}$ & $\begin{array}{c}10.80^{* * *} \\
(1.79)\end{array}$ \\
\hline Observations & 914 & 914 & 914 & 914 & 914 & 914 & 913 & 913 & 914 & 914 \\
\hline Treatment Condition & No & No & Yes & Yes & Yes & Yes & Yes & Yes & Yes & Yes \\
\hline $\begin{array}{l}\text { Includes Treatment } \\
\text { Interaction }\end{array}$ & No & No & No & Yes & No & Yes & No & Yes & No & Yes \\
\hline
\end{tabular}

Table shows output for regressions. Standard errors are in parentheses. ${ }^{* * *},{ }^{* *}$, and ${ }^{*}$ indicate significance at the 1, 5, and 10 percent critical level. Standard errors are clustered at he respondent level.

\footnotetext{
4 "A bat and a ball cost INR 110 in total. The bat costs INR 100 more than the ball. How much does the ball cost?" See appendix for the other measures
} 


\subsection{Economic Preferences}

This grouping also includes several canonical measures taken from Kahneman and Tversky, and others that have been popularized by more recent highly published behavioral economists (Thaler and Sunstein, 2009; Ariely and Jones, 2008). All measures are significant for the pooled sample and several - such as those for the common ratio effect, the decoy effect, defaults on incentivised choice, and present bias show predictably strong effects across each sub-sample. Evidence of mental accounting, however, is only present in the student sample, where this group is far less likely to buy a new movie ticket in the event of losing a ticket relative to losing an equivalent value of cash (given that the movie ticket was more naturally placed into a 'mental account' than the money, and therefore losing it exhausted the allotment to this mental account). This effect did not exist for the low-income sample. Furthermore, though both sub-samples show significant signs of bias in the "common ratio effect", this effect is significantly larger for the student sub-sample than the low-income sub-sample.

Table 3: Regression Output for Biases Related to "Economic Preferences"

\begin{tabular}{|c|c|c|c|c|c|c|c|c|}
\hline & \multirow{2}{*}{$\frac{\text { Common Ratio }}{(1)}$} & \multirow{2}{*}{$\frac{\text { Present Bias }}{(2)}$} & \multicolumn{2}{|c|}{ Ment. Accounting } & \multicolumn{2}{|c|}{ Default Charity } & \multicolumn{2}{|c|}{ Decoy } \\
\hline & & & $(3)$ & $(4)$ & $(5)$ & $(6)$ & $(7)$ & $(8)$ \\
\hline \multicolumn{9}{|c|}{ Without Controls } \\
\hline Differential Effect for Student & $\begin{array}{c}0.22^{* * *} \\
(0.03)\end{array}$ & $\begin{array}{l}-0.00 \\
(0.03)\end{array}$ & & $\begin{array}{c}-0.21^{* * *} \\
(0.06)\end{array}$ & & $\begin{array}{l}-0.00 \\
(0.06)\end{array}$ & & $\begin{array}{l}-0.01 \\
(0.06)\end{array}$ \\
\hline Treatment & & & $\begin{array}{c}-0.14^{* * *} \\
(0.03)\end{array}$ & $\begin{array}{l}-0.03 \\
(0.05)\end{array}$ & $\begin{array}{c}0.08^{* * *} \\
(0.03)\end{array}$ & $\begin{array}{l}0.08^{*} \\
(0.05)\end{array}$ & $\begin{array}{c}0.19^{* * *} \\
(0.03)\end{array}$ & $\begin{array}{c}0.21^{* * *} \\
(0.04)\end{array}$ \\
\hline Student Dummy & & & & $\begin{array}{c}0.28^{* * *} \\
(0.05)\end{array}$ & & $\begin{array}{l}-0.01 \\
(0.05)\end{array}$ & & $\begin{array}{c}-0.15^{* * *} \\
(0.04)\end{array}$ \\
\hline Constant & $\begin{array}{c}0.14^{* * *} \\
(0.02)\end{array}$ & $\begin{array}{c}0.40^{* * *} \\
(0.02)\end{array}$ & $\begin{array}{c}0.51^{* * *} \\
(0.02)\end{array}$ & $\begin{array}{c}0.36^{* * *} \\
(0.03)\end{array}$ & $\begin{array}{c}0.64^{* * *} \\
(0.02)\end{array}$ & $\begin{array}{c}0.65^{* * *} \\
(0.04)\end{array}$ & $\begin{array}{c}0.64^{* * * *} \\
(0.02)\end{array}$ & $\begin{array}{c}0.71^{* * *} \\
(0.03)\end{array}$ \\
\hline Observations & 914 & 914 & 914 & 914 & 914 & 914 & 914 & 914 \\
\hline \multicolumn{9}{|c|}{ Including Controls } \\
\hline Differential Effect for Student & $\begin{array}{c}0.17^{* * *} \\
(0.06)\end{array}$ & $\begin{array}{c}0.01 \\
(0.07)\end{array}$ & & $\begin{array}{c}-0.22^{* * *} \\
(0.07)\end{array}$ & & $\begin{array}{l}-0.01 \\
(0.06)\end{array}$ & & $\begin{array}{l}-0.02 \\
(0.06)\end{array}$ \\
\hline Treatment & & & $\begin{array}{c}-0.13^{* * *} \\
(0.03)\end{array}$ & $\begin{array}{l}-0.02 \\
(0.05)\end{array}$ & $\begin{array}{c}0.08^{* *} \\
(0.03)\end{array}$ & $\begin{array}{l}0.09^{*} \\
(0.05)\end{array}$ & $\begin{array}{c}0.20^{* * *} \\
(0.03)\end{array}$ & $\begin{array}{c}0.21^{* * *} \\
(0.04)\end{array}$ \\
\hline Student Dummy & & & $\begin{array}{c}0.14^{* *} \\
(0.07)\end{array}$ & $\begin{array}{c}0.23^{* * *} \\
(0.07)\end{array}$ & $\begin{array}{l}-0.04 \\
(0.06)\end{array}$ & $\begin{array}{l}-0.04 \\
(0.07)\end{array}$ & $\begin{array}{c}-0.22^{* * *} * \\
(0.06)\end{array}$ & $\begin{array}{c}-0.22^{* * *} \\
(0.06)\end{array}$ \\
\hline Constant & $\begin{array}{c}0.65^{* *} \\
(0.31) \\
\end{array}$ & $\begin{array}{c}0.38 \\
(0.36) \\
\end{array}$ & $\begin{array}{c}0.42 \\
(0.36) \\
\end{array}$ & $\begin{array}{c}0.37 \\
(0.36)\end{array}$ & $\begin{array}{c}0.93^{* * *} \\
(0.34)\end{array}$ & $\begin{array}{c}0.93^{* * *} \\
(0.34)\end{array}$ & $\begin{array}{l}0.60^{*} \\
(0.32)\end{array}$ & $\begin{array}{l}0.60^{*} \\
(0.32)\end{array}$ \\
\hline Observations & 914 & 914 & 914 & 914 & 914 & 914 & 914 & 914 \\
\hline Treatment Condition & No & No & Yes & Yes & Yes & Yes & Yes & Yes \\
\hline Includes Treatment Interaction & No & No & No & Yes & No & Yes & No & Yes \\
\hline
\end{tabular}

Table shows output for regressions. Standard errors are in parentheses. ${ }^{* * *},{ }^{* *}$, and ${ }^{*}$ indicate significance at the 1, 5, and 10 percent critical level. Standard errors are clustered at he respondent level. 


\section{Discussion and Conclusion}

Overall, the results of this study suggest that our Indian populations of interest - low-income citizens liable to be targeted in development programs, and elite university students - predominantly display the behavioral biases from the behavioral economics literature. This suggests that these biases are not exclusively peculiarities of 'WEIRD' sampling bias. The effects are significant for the majority of measures in the hypothesized direction. For most, the direction is the same for each sub-sample, the magnitude of effects is pronounced, and in many cases the point estimates are similar to those for Western samples (Ariely and Jones, 2008; Kahneman and Tversky, 1979; Cohen et al., 2020; Frederick, 2005; Kahneman, 2011). For instance, the proportion of the sample showing present-biased time preferences (40\%) over money tightly accords with the seminal literature on this phenomenon, (that finds that between $35 \%$ and $45 \%$ of typical samples are present-biased; (Cohen et al., 2020)), while the results for the student sample for the cognitive reflection test are nearly identical to that for student samples in the original study (40\% correct answers compared to $43 \%$ respectively; Frederick (2005)). Similarly, the effect sizes for loss framing, the representativeness heuristic and the decoy effect (for both samples), and the common ratio effect and mental accounting (for students only), are slightly smaller than but within a reasonable range of reported effect sizes from the original and subsequent validation studies (Frederick, 2005; Ariely and Jones, 2008; Kahneman and Tversky, 1984; Tversky and Kahneman, 1983; Kahneman, 2011; Olsen et al., 2019; Diederich et al., 2018). The anchoring effect in this study actually exceeds those typically found in the literature (we find an anchoring index of approximately 0.8 compared to roughly $0.5-0.6$ across other studies (Kahneman, 2011)). Therefore, in spite of the existing evidence of observed differences in reasoning patterns, social preferences, and other differences in cognition and behavior (Henrich et al., 2010c; Falk et al., 2018), the results from this study show encouraging replication potential for some of the more fundamental behavioral biases.

These results are also consistent with some of the large-scale replication work in behavioral economics and similar disciplines. Camerer et al. (2016) replicate 18 behavioral economics experimental effects published in prominent economics journals between 2011 and 2014 and observe a $66 \%$ replication rate - slightly lower than but similar to that observed in this study. Klein et al. (2018) run a large replication project across multiple countries, including a number in the Global South, to test several of the seminal social psychology findings. Though they find a lower replication rate than this study (approximately 50\%), they find little heterogeneity between WEIRD and 'less-WEIRD' (including middle-income countries) subsamples, suggesting that the effects that 'survive' replication do not differ systematically by nationality.

In spite of the surprising lack of systematic differences, we still observe clear heterogeneity in a subset of measures. Heterogeneity in effects for the common ratio effect and mental accounting suggest that some biases can vary across different sub-national populations in important ways. Notably, the effects for the elite student sample are practically similar to estimates on Western samples for both measures, while the low income group shows significantly less or no bias. The result for mental accounting for the student sample is also in sharp contrast to a recent study that uses the exact same measure amongst an elite Indian student sample (Banerjee et al., 2019) and finds no sign of mental accounting. However, the sample for this study, of 67 , is far less than ours, of 457, and their use of inference to confirm a null hypothesis is not appropriate. The findings for both the common ratio effect and mental accounting also support 
some existing evidence that biases regarding small differences in monetary amounts are less pronounced among lower-income groups compared to higher income groups. Mental accounting, specifically, has been more strongly observed for those with higher incomes and less for those facing conditions of financial scarcity (Olsen et al., 2019; Muehlbacher and Kirchler, 2019). Evidence also shows that those facing financial scarcity tend to pay more attention to small differences in monetary outcomes and are therefore more likely to act rationally over them (Mullainathan and Shafir, 2013). Taken together, this suggests that research on similar economic preferences should explore socio-economic heterogeneity as a primary component of research designs.

Overall, this study provides evidence that these biases exist in non-WEIRD populations. However, it cannot make any claims about their universality. Future work should explore the replicability of and heterogeneity in these and similar measures. Robust large-sample and cross-country studies are needed to map these biases across a broader range of regions and sub-national groups, preferably with representative samples. 'Multi-lab' studies provide a possible facility for this. However, these studies need to do more to access non-student populations and more funding needs to be made available for theoretical work in the global south for this to happen. At the least, even if universality is far away, we can support the claim that these biases are not just WEIRD. 


\section{References}

Maurice Allais. Le comportement de l'homme rationnel devant le risque: critique des postulats et axiomes de l'école américaine. Econometrica: Journal of the Econometric Society, pages 503-546, 1953.

Dan Ariely and Simon Jones. Predictably irrational. Harper Audio New York, NY, 2008.

Jeffrey J Arnett. The neglected 95\%: why american psychology needs to become less american. 2016.

Pronobesh Banerjee, Promothesh Chatterjee, Sanjay Mishra, and Anubhav A Mishra. Loss is a loss, why categorize it? mental accounting across cultures. Journal of Consumer Behaviour, 18(2):77-88, 2019.

H Clark Barrett, Alexander Bolyanatz, Alyssa N Crittenden, Daniel MT Fessler, Simon Fitzpatrick, Michael Gurven, Joseph Henrich, Martin Kanovsky, Geoff Kushnick, Anne Pisor, et al. Small-scale societies exhibit fundamental variation in the role of intentions in moral judgment. Proceedings of the National Academy of Sciences, 113(17):4688-4693, 2016.

Colin F Camerer, Anna Dreber, Eskil Forsell, Teck-Hua Ho, Jürgen Huber, Magnus Johannesson, Michael Kirchler, Johan Almenberg, Adam Altmejd, Taizan Chan, et al. Evaluating replicability of laboratory experiments in economics. Science, 351(6280):1433-1436, 2016.

Jonathan Cohen, Keith Marzilli Ericson, David Laibson, and John Myles White. Measuring time preferences. Journal of Economic Literature, 58(2):299-347, 2020.

Adele Diederich, Marc Wyszynski, and Ilana Ritov. Moderators of framing effects in variations of the asian disease problem: Time constraint, need and disease type. Judgment and decision making, 13(6): $529,2018$.

Isaac Dinner, Eric J Johnson, Daniel G Goldstein, and Kaiya Liu. Partitioning default effects: why people choose not to choose. Journal of Experimental Psychology: Applied, 17(4):332, 2011.

Armin Falk, Anke Becker, Thomas Dohmen, Benjamin Enke, David Huffman, and Uwe Sunde. Global evidence on economic preferences. The Quarterly Journal of Economics, 133(4):1645-1692, 2018.

Ernst Fehr and Urs Fischbacher. Why social preferences matter-the impact of non-selfish motives on competition, cooperation and incentives. The economic journal, 112(478):C1-C33, 2002.

Shane Frederick. Cognitive reflection and decision making. Journal of Economic perspectives, 19(4): 25-42, 2005.

Pamela W Henderson and Robert A Peterson. Mental accounting and categorization. Organizational Behavior and Human Decision Processes, 51(1):92-117, 1992.

Joseph Henrich, Jean Ensminger, Richard McElreath, Abigail Barr, Clark Barrett, Alexander Bolyanatz, Juan Camilo Cardenas, Michael Gurven, Edwins Gwako, Natalie Henrich, et al. Markets, religion, community size, and the evolution of fairness and punishment. science, 327(5972):1480-1484, 2010a.

Joseph Henrich, Steven J Heine, and Ara Norenzayan. Most people are not weird. Nature, 466(7302): 29-29, 2010b. 
Joseph Henrich, Steven J Heine, and Ara Norenzayan. The weirdest people in the world? Behavioral and brain sciences, 33(2-3):61-83, 2010c.

Joel Huber, John W Payne, and Christopher Puto. Adding asymmetrically dominated alternatives: Violations of regularity and the similarity hypothesis. Journal of consumer research, 9(1):90-98, 1982.

Eric J Johnson and Daniel Goldstein. Do defaults save lives?, 2003.

Daniel Kahneman. Thinking, fast and slow. Macmillan, 2011.

Daniel Kahneman and Amos Tversky. Prospect theory: An analysis of decision under risk. Econometrica, 47(2):263-292, 1979.

Daniel Kahneman and Amos Tversky. Choices, values, and frames. American Psychologist, 39(4):341, 1984.

Richard A Klein, Michelangelo Vianello, Fred Hasselman, Byron G Adams, Reginald B Adams Jr, Sinan Alper, Mark Aveyard, Jordan R Axt, Mayowa T Babalola, Štěpán Bahník, et al. Many labs 2: Investigating variation in replicability across samples and settings. Advances in Methods and Practices in Psychological Science, 1(4):443-490, 2018.

Rachid Laajaj, Karen Macours, Daniel Alejandro Pinzon Hernandez, Omar Arias, Samuel D Gosling, Jeff Potter, Marta Rubio-Codina, and Renos Vakis. Challenges to capture the big five personality traits in non-weird populations. Science advances, 5(7):eaaw5226, 2019.

David Laibson. Golden eggs and hyperbolic discounting. The Quarterly Journal of Economics, 112(2): 443-478, 1997.

Blakeley B McShane, Jennifer L Tackett, Ulf Böckenholt, and Andrew Gelman. Large-scale replication projects in contemporary psychological research. The American Statistician, 73(sup1):99-105, 2019.

Stephan Muehlbacher and Erich Kirchler. Individual differences in mental accounting. Frontiers in Psychology, 10, 2019.

Sendhil Mullainathan and Eldar Shafir. Scarcity: Why having too little means so much. Macmillan, 2013.

Jinkyung Na, Igor Grossmann, Michael EW Varnum, Shinobu Kitayama, Richard Gonzalez, and Richard E Nisbett. Cultural differences are not always reducible to individual differences. Proceedings of the National Academy of Sciences, 107(14):6192-6197, 2010.

Richard E Nisbett, Kaiping Peng, Incheol Choi, and Ara Norenzayan. Culture and systems of thought: holistic versus analytic cognition. Psychological review, 108(2):291, 2001.

Jerome Olsen, Matthias Kasper, Christoph Kogler, Stephan Muehlbacher, and Erich Kirchler. Mental accounting of income tax and value added tax among self-employed business owners. Journal of Economic Psychology, 70:125-139, 2019.

N Craig Smith, Daniel G Goldstein, and Eric J Johnson. Choice without awareness: Ethical and policy implications of defaults. Journal of Public Policy \& Marketing, 32(2):159-172, 2013. 
Fritz Strack, Leonard L Martin, and Norbert Schwarz. Priming and communication: Social determinants of information use in judgments of life satisfaction. European journal of social psychology, 18(5):429$442,1988$.

Richard Thaler. Mental accounting and consumer choice. Marketing science, 4(3):199-214, 1985.

Richard H Thaler. From cashews to nudges: The evolution of behavioral economics. American Economic Review, 108(6):1265-87, 2018.

Richard H Thaler and Cass R Sunstein. Nudge: Improving decisions about health, wealth, and happiness. Penguin, 2009.

Michael Tomasello, Malinda Carpenter, Josep Call, Tanya Behne, and Henrike Moll. Understanding and sharing intentions: The origins of cultural cognition. Behavioral and brain sciences, 28(5):675-691, 2005.

Amos Tversky and Daniel Kahneman. Judgment under uncertainty: Heuristics and biases. science, 185 (4157):1124-1131, 1974.

Amos Tversky and Daniel Kahneman. Extensional versus intuitive reasoning: The conjunction fallacy in probability judgment. Psychological review, 90(4):293, 1983. 


\section{Appendix}

\section{Appendix 1 - Measures}

\section{Cognitive Reflection Test}

The Cognitive Reflection Test (CRT) is a 3-item test designed to create a conflict between an automatic intuitive response and a reflective reasoned response on all three items. Together, they present a measure of a respondent's engagement with their reflective capacities. All three questions present a relatively simple mathematical question which has an intuitive response that is wrong, and a correct response which requires some reasoning. In the original study, respondents got 1.23 out of 3 correct on average (Frederick, 2005). In this study, all respondents will complete the same three questions.

- Instruction: "On the next pages, you will be asked several questions that vary in their difficulty. Please answer as quickly and as accurately as you can."

\section{- Questions / Tasks:}

- A bat and a ball cost INR 110 in total. The bat costs INR 100 more than the ball. How much does the ball cost? (answer in rupees)

- If it takes 5 machines 5 minutes to make 5 buttons, how long would it take 100 machines to make 100 buttons? (answer in minutes)

- In a lake, there is a patch of lotus flowers. Every day, the patch doubles in size. If it takes 48 days for the patch to cover the entire lake, how long would it take for the patch to cover half of the lake? (answer in days)

- Proposed Analytical Procedure: The main variable of interest is the number of correct responses. A secondary variable of interest is an indicator for responding Rs10 for the first question, 100 minutes for the second question, and 24 days for the third question.

\section{Representativeness Heuristic}

Tversky and Kahneman (1983) gave a group of undergraduates the following set of descriptions about an individual named Linda: "Linda is 31 years old, single, outspoken and very bright. She majored in philosophy. As a student, she was deeply concerned with issues of discrimination and social justice, and also participated in anti-nuclear demonstrations." Respondents were then asked to rank the probability that Linda was involved with certain organizations or occupations including the likelihood that Linda was a "bank teller", "active in the feminist movement", and that Linda was both "a bank teller and active in the feminist movement." Tversky and Kahneman found that undergraduates rated the probability that Linda was both a bank teller and active in the feminist movement as higher than that of Linda being a bank teller, despite the fact that the former category of individuals is a subset of the latter. We use a modified version of this that applies the same principles in generating both the profile and the possible outcomes to be ranked. In our version, we created the profile of a 'typical' liberal and educated Indian woman, and a list of current occupations that capture a range of probabilities. Importantly, we combine an option of an unintuitive outcome ("Preeti is a garment retailer"), with an option that has intuitive 
association with the profile of Preeti - ie. the combined options appear to better 'represent' her, though is by definition less likely that the unintuitive outcome alone. We also reduce the total options from 8 to 5, allowing for variation in ranks but reducing the computational and logistical difficulties of sorting 8 options. This measure was developed through qualitative exercises with respondents and piloted.

- Instruction: "On the following page, you will be asked to evaluate a profile of a hypothetical individual. Please click through to continue."

- Questions / Tasks: Preeti is 30 years old; she did very well at school, is independent, and always speaks her mind. At university, she studied a degree in Politics, and was the president of the student union. She cares deeply about her community and wants them to grow and succeed. Please rank the following possibilities by how likely they are to describe Preeti, where 1 is the most likely to describe her, and 5 is the least likely to describe her.

1. Preeti is a teacher in primary school

2. Preeti volunteers for a local NGO

3. Preet is a garment retailer

4. Preeti works in a call center

5. Preeti is a garment retailer and volunteers for a local NGO

- Proposed Analytical Procedure: TThe variable of interest is a dummy variable taking the value of 1 if the respondent has selected option 5 to be more likely than option 3 .

\section{Mood Heuristic}

The mood heuristic is a cognitive shortcut by which an individual's subjective impressions about the goodness or badness of an event, object, or idea informs their judgments and decision-making. Specifically, individuals allow how they 'feel' at a given moment to affect more universal assessments. We model our measure on that used by Strack et al. (1988) and adapt it to the local context as it includes culturally specific reference points. The original measure uses a personal numerical prime - asking respondents 'how many dates they went on in the past month' - that is correlated with positive affect. They are then asked about their general life satisfaction. The mood prime induces a positive affective state which influences life satisfaction assessments. The control condition receives the same questions with the life satisfaction question asked first. In the original study, the 'number of dates' correlates strongly with life satisfaction when asked first and not when asked second. We substitute a similar, and more contextually appropriate mood prime by asking "How many times did someone you know do a favour for you in the last week?".

- Instruction: "You will now be asked to think about a situation, followed by several questions. Please answer as carefully and accurately as possible"

\section{- Questions / Tasks:}

- No prime condition: 
* How happy are you with life in general? Please rate your general happiness on a scale from 1 to 11, where 1 is 'not so happy' and 11 is 'extremely happy' - you can choose any number between 1 and 11 .

* How happy do you feel right now? Please rate your happiness right now on a scale from 1 to 11 , where 1 is 'not so happy' and 11 is 'extremely happy' - you can choose any number between 1 and 11 .

* How many times did someone you know do a favour for you in the last week?

- Mood prime condition:

* How many times did someone you know do a favour for you in the last week?

* How happy are you with life in general? Please rate your general happiness on a scale from 1 to 11, where 1 is 'not so happy' and 11 is 'extremely happy' - you can choose any number between 1 and 11 .

* How happy do you feel right now? Please rate your happiness right now on a scale from 1 to 11 , where 1 is 'not so happy' and 11 is 'extremely happy' - you can choose any number between 1 and 11 .

- Proposed Analytical Procedure: Given that this analysis, unlike others, relies on the relationship of the numeric prime response to the life satisfaction outcome conditional on treatment, rather than simply treatment condition, it warrants it's own specification (TBA)

\section{Anchoring}

Anchoring refers to the tendency of individuals to overweight the first piece of information available to them in making decisions (Tversky and Kahneman, 1974). In the classic experiment, Tversky and Kahneman asked participants to compute the product of the numbers 1 through 8 in five seconds. Because participants were unable to solve the task in five seconds, they had to estimate the rest of the product using the information available to them - namely, the value of the product up to the point where they had stopped. Subject who were asked to multiply 1 through 8 produced much smaller estimates of the final product than subjects who were asked to multiply 8 through 1 . Because subjects in the first condition began by multiplying much smaller numbers together, they relied on a smaller anchor to produce their final estimate. We use a modified version of this task in which we ask respondents to give a price estimate for a particular product after being exposed to either a high or low anchor. Procedure: A random half of the sample is given a low-anchor to estimate the price of a Snuggie Microplush product. Respondents are subsequently asked to give an exact price for the product. The other half of the sample is given a high-anchor, and subsequently asked to give an exact price for the product.

- Instruction: "In the next phase, you will be asked to evaluate a product. Please click through to continue."

\section{- Questions / Tasks:}


- Low Anchor Condition: "What is your best estimate of the price of the product below?" (Picture shown of Snuggie Microplush)

* More than INR $700(1)$

* Less than INR $700(2)$

- Low Anchor Condition: "What is your exact estimate of the price?"

- High Anchor Condition: "What is your best estimate of the price of the product below?" (Picture shown of Snuggie Microplush)

* More than INR 1500 (1)

* Less than INR $1500(2)$

- High Anchor Condition: "What is your exact estimate of the price?"

- Proposed Analytical Procedure: The variable of interest is the exact estimate of price. The "high anchor condition" will be considered the treatment condition

\section{Loss and Gain Framing}

Kahneman and Tversky (1984) showed that framing the same problem as either a gain or a loss can result in subjects changing their preferences. A well-known example is the Asian Disease Problem, which we use here. In the original study, participants were asked to "imagine that the U.S. is preparing for the outbreak of an unusual Asian disease, which is expected to kill 600 people. Two alternative programs to combat the disease have been proposed..." One group of participants was given the choice to either save 200 people in a group of 600 people, or choose a probabilistic option by which there is a $1 / 3$ probability that 600 people will be saved, and a $2 / 3$ probability that no people will be saved. In the original study, 72 percent of participants preferred the safe option. Another group of participants were confronted with an identical problem (in terms of expected values), but were told to choose between an option in which 400 people would die, or a probabilistic scenario in which there is a $1 / 3$ probability that nobody will die, and a $2 / 3$ probability that 600 people will die. When framed as a loss, 78 percent preferred the risky option. Kahneman Tversky later formalized these findings ask risk aversion in the gain domain and risk-seeking in the loss domain. We modify this version slightly to make the probability as instead of and adjust the safe amount to 300 in order to make this computationally as simple as possible but maintain the equivalence of expected value - we also slightly modify the framing of probability to make it more simple, but maintain its accuracy.

- Instruction: "On the following page, you will be asked to read a scenario and determine a response. Please read the scenario and options carefully. Click through to continue"

\section{- Questions / Tasks:}

- Gain Frame Condition:" "Imagine that India is preparing for the outbreak of an unusual African disease, which is expected to kill 600 people. Two alternative programs to combat the disease have been proposed. Assume that the exact scientific estimate of the consequences are as 
follows: If Program A is adopted, 300 people will be saved. If Program B is adopted, there is a 1 in 2 chance that 600 people will be saved, and a 1 in 2 chance that no people will be saved

- this is the same as if we flipped a coin - if the coin landed heads 600 people will be saved, if the coin landed tails no people will be saved." Which of the two programs would you favor?"

* Program A (1)

* Program B (2)

- Loss Frame Condition: "Imagine that India is preparing for the outbreak of an unusual African disease, which is expected to kill 600 people. Two alternative programs to combat the disease have been proposed. Assume that the exact scientific estimate of the consequences are as follows: If Program A is adopted, 300 people will die. If Program B is adopted, there is a 1 in 2 chance that nobody will die, and a 1 in 2 chance that 600 people will die - this is the same as if we flipped a coin - if the coin landed heads nobody will die, if the coin landed tails 600 people will die. Which of the two programs would you favor?

* Program A (1)

* Program B (2)

- Proposed Analytical Procedure: The variable of interest is the exact estimate of price. The "high anchor condition" will be considered the treatment condition

\section{Common Ratio Effect}

The Common Ratio Effect describes a famous violation of the expected utility model of decision-making under risk. It was first discussed by Allais (1953) and popularized by Kahneman and Tversky (1979) in the following example. Imagine a participant is confronted with the following choice problems:

Problem 1

1. Receive $\$ 4,000$ with probability 0.8 (and $\$ 0$ with probability 0.2 )

2. Receive $\$ 3,000$ with certainty

Problem 2

1. Receive $\$ 4,000$ with probability 0.20 (and $\$ 0$ with probability 0.8 )

2. Receive $\$ 3,000$ with probability 0.25 (and $\$ 0$ with probability 0.75 )

Because the amounts are identical and the probabilities in Problem 2 are exactly one-fourth of those in Problem 1, expected utility predicts consistent choices in the two problems, i.e. (1a 2a) or (1b 2b). Instead, experimental evidence shows humans robustly prefer choice set (1b and $2 \mathrm{a}$ ). We test a variant of this task (see appendix for exact instrument). The variable of interest is a dummy indicating whether a participant chose (1b and $2 \mathrm{a})$.

- Instruction: "On the following pages, you will be asked to make hypothetical financial decisions between lotteries that have different chances of being implemented. Please pick the option that you 
would prefer the most."

- Questions / Tasks:

1. Which option do you prefer?

(a) $25 \%$ chance of receiving INR 250,000 .

(b) $50 \%$ chance of receiving INR 100,000.

2. Which option do you prefer?

(a) $2.5 \%$ chance of receiving INR 250,000 .

(b) $5 \%$ chance of receiving INR 100,000.

- Proposed Analytical Procedure: The variable of interest is a dummy indicating whether a participant chose (1b and 2a). A secondary variable of interest is a dummy for choosing (1a and $2 \mathrm{~b})$

\section{Intertemporal Choice and Present Bias}

Studies on intertemporal choice have found that humans show a systematic preference for rewards to materialize sooner rather than later. In the canonical discounted expected utility model, humans discount future rewards exponentially, i.e. at a constant rate. Numerous experiments have shown that intertemporal preferences are more accurately described by a hyperbolic model (Laibson, 1997), in which the value of a reward falls rapidly in the near future, but more slowly in the distant future. For example, humans tend to prefer 10todayover 11 tomorrow, but prefer 11in101daysover 10 in 100 days. In other words, the initial preference for immediacy is attenuated or reversed when rewards are delayed further out into the future. We ask a similar pair of questions to all respondents.

- Instruction: "On the following pages, you will be asked to make hypothetical financial decisions in which you would receive payments at different points in time. Please pick the option that you would prefer the most. Imagine that this money will be transferred to, or taken out of, your bank account automatically, so you do not have to keep track of it or perform any actions to get it. You simply have to decide. Please respond as if you were deciding about real money."

- Questions / Tasks:

1. Which option do you prefer?

(a) Receive INR 2000 today.

(b) Receive INR 2500 in one month.

2. Which option do you prefer?

(a) Receive INR 2000 in ten months.

(b) INR 2500 in eleven months. 
- Proposed Analytical Procedure: The variable of interest is a dummy that is equal to 1 if a respondent shows "decreasing impatience", i.e. chooses "Receive INR 2000 today" and "Receive INR 2500 in eleven months". For any other combination, the value of the dummy variable is set to zero. Secondary variables will be a dummy for "increasing impatience," and "Consistent patience

\section{Defaults - Charity Selection}

A default describes an option that is pre-chosen, and ultimately selected if the decision-maker does not specify an active choice. Research shows that defaults can generate meaningful differences in choices, in spite of its lack of relevance to the decision-makers' preferences or the information on the choice parameters. Changing the default option in a choice context has been known to dramatically increasing willingness to donate organs after death (Johnson and Goldstein, 2003; Dinner et al., 2011). We design our own measure modelled on those described in Smith et al. (2013), which describes a set of highly common default options for online purchases, and present a simple incentivised binary choice between two options where participants are likely to have different yet meaningful preferences to test the effect of defaults in the Indian context.

- Instruction: "On the following page, you will be asked to choose between two options. Please mark your choice clearly on the page. Busara and the Center for Social and Behavioral Change will be making a donation to a charity based on which charity you prefer. The charity with the most votes from people involved in this study will receive a donation at the end of this study. Which of the following two charities would you prefer to receive this donation?"

\section{- Questions / Tasks:}

- Oxfam Default

* Oxfam International - a charity focused on reducing poverty around the world [preselected]

* Pratham - an Indian charity focused on improving education in India

- Pratham Default

* Oxfam International - a charity focused on reducing poverty around the world

* Pratham - an Indian charity focused on improving education in India [pre-selected]

- Proposed Analytical Procedure: The dependent variable is selection of Pratham, and the treatment condition is the 'Pratham default' condition.

\section{Mental Accounting}

Mental accounting describes the concept where people assign money to different 'mental accounts'. Money, however, is fungible and standard economic theory suggests it is most efficient to allocate money without restriction across all categories of spending. Kahneman and Tversky (1984) demonstrated this in a study where participants were more willing to spend $\$ 10$ on a movie ticket if they had just lost $\$ 10$ than if they had to replace a lost $\$ 10$ movie ticket. The explanation for this is that people have separate mental 
accounts for transactions specifically related to the movie, and would behave differently if the value lost can be attributed to this 'account'. Henderson and Peterson (1992) repeated this measure with significant results. Banerjee et al. (2019) also used an adapted version of this measure with a very small sample in India. We use their version, which closely mirrors Kahneman and Tversky's measure, with price adjustments and a larger sample size.

Procedure: A randomly selected half of respondents will be assigned a hypothetical scenario where they 'lost Rs. 200 cash' and the other half randomly assigned a hypothetical scenario where they "lost the ticket'. In each case respondents are then asked if they would still purchase another ticket.

- Instruction: "On the following page, you will be asked to read a scenario and determine a response. Please read the scenario and options carefully. Click through to continue."

\section{- Questions / Tasks:}

- Condition 1 Imagine that you have decided to see a movie where admission is Rs. 200 per ticket. As you enter the theater, you realize that you have lost Rs. 200 cash. Will you still pay Rs. 200 for a ticket for the play?

* Yes

* No

- Condition 1 Imagine that you have decided to see a movie where admission is Rs. 200 per ticket. As you enter the theater, you realize that you have lost the ticket. Will you still pay Rs. 200 for a ticket for the play?

* Yes

* No

- Proposed Analytical Procedure: The dependent variable of interest is a dummy variable taking the value 1 if the respondent chooses "Yes" to purchase the new ticket. The treatment variable is being assigned to the "Lost Ticket" condition.

\section{Decoy (Attraction) Effect}

The Attraction Effect (also known as the Decoy Effect) was first identified by Huber et al. (1982) and describes the phenomenon by which the introduction of an irrelevant third option changes an individual's preference between two other options. We use the most popular example of this effect, due to Ariely and Jones (2008) which uses a decoy option of "print subscription" when offering a choice between a "web subscription" and a "print web subscription" to the Economist magazine. The premise is that the "print subscription" option is weakly dominated by the "print web subscription" option, and so should never be chosen, as such acting like a 'decoy'. Procedure: Half of the respondents are given a set of possible preferences with a decoy option, while the other half of respondents are given a set of possible preferences with no such decoy. 
- Instruction: "On the following page, you will be asked to make a simple purchasing decision. Please pick the option that you prefer the most."

- Questions / Tasks:

- Decoy Condition Which option do you prefer?

1. A money holder from a local retailer for INR 300

2. A bag from a local retailer for INR 800

3. A bag and a money holder from a local retailer INR 800

- No Decoy Condition Which option do you prefer?

1. A money holder from a local retailer for INR 300

2. A bag and a money holder from a local retailer INR 800

- Proposed Analytical Procedure: The variable of interest is a dummy variable that takes the value of 1 if a respondent has selected "A bag and a money holder from a local retailer INR 800" as their preferred option. The "decoy condition" is considered the treatment group. 


\section{Appendix 2 - Individual Bar Graphs}

\section{Judgements and Reasoning}

Figure A1: Representativeness Heuristic

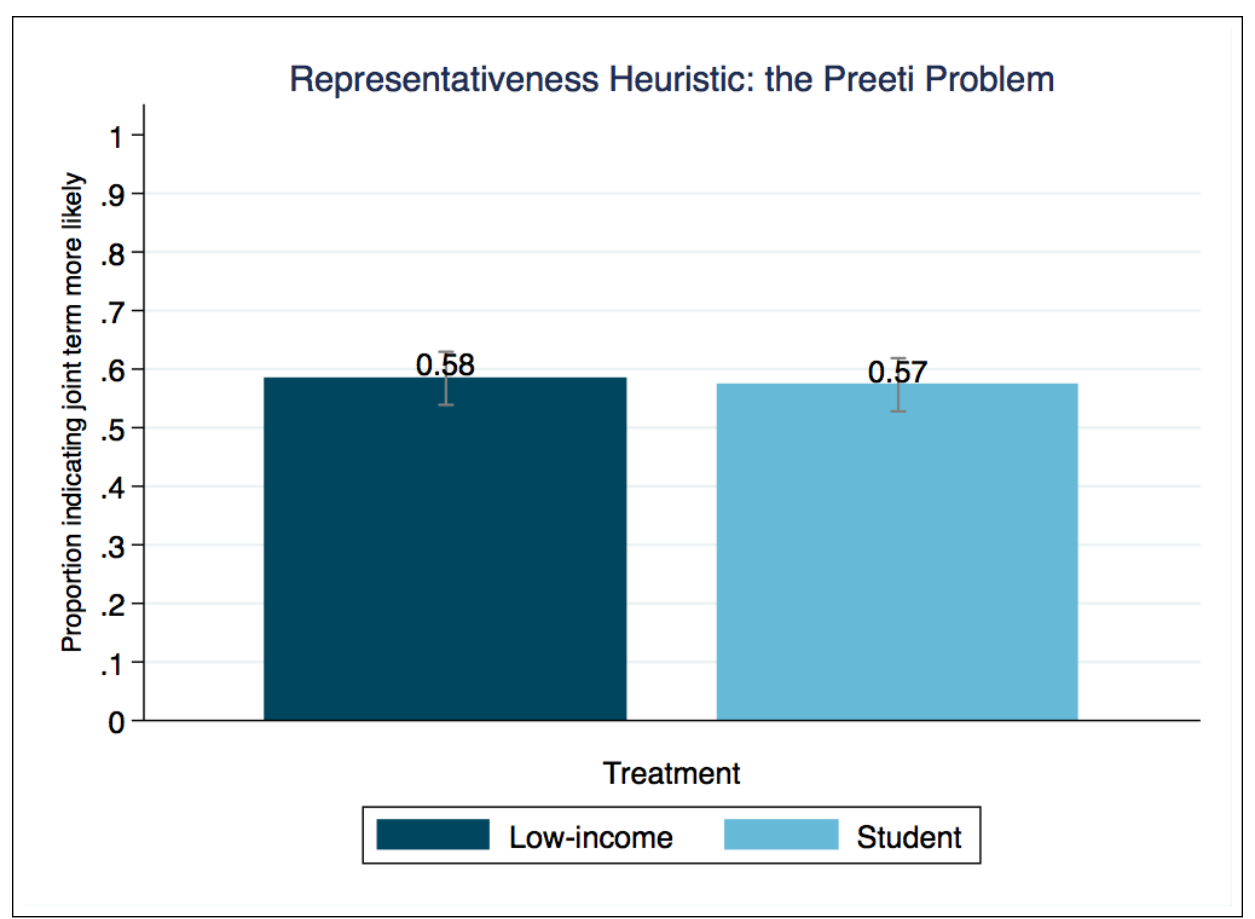

Bars represent the proportion making the error

Figure A2: Cognitive Reflection Test

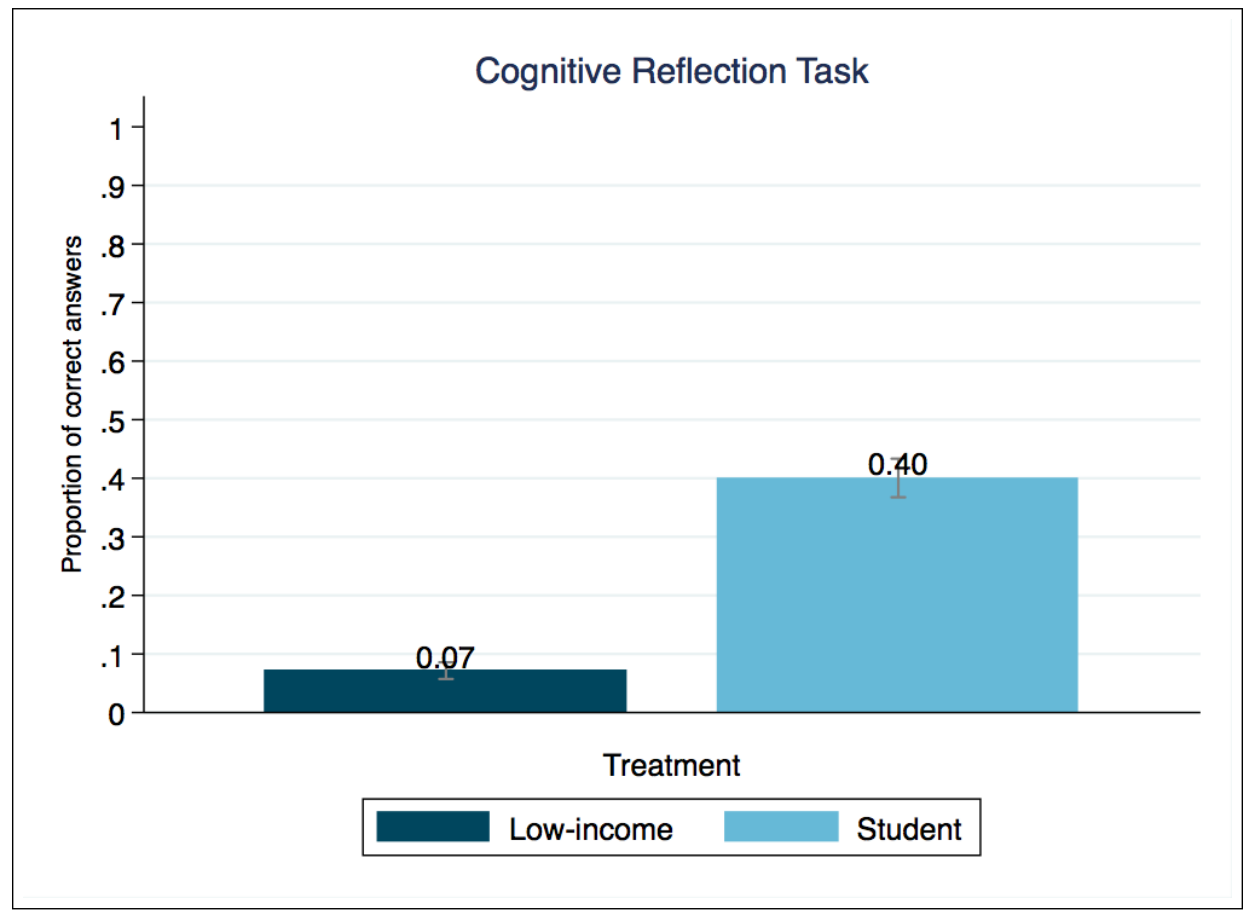

Bars represent the proportion of questions correct 
Figure A3: Framing: Loss Aversion

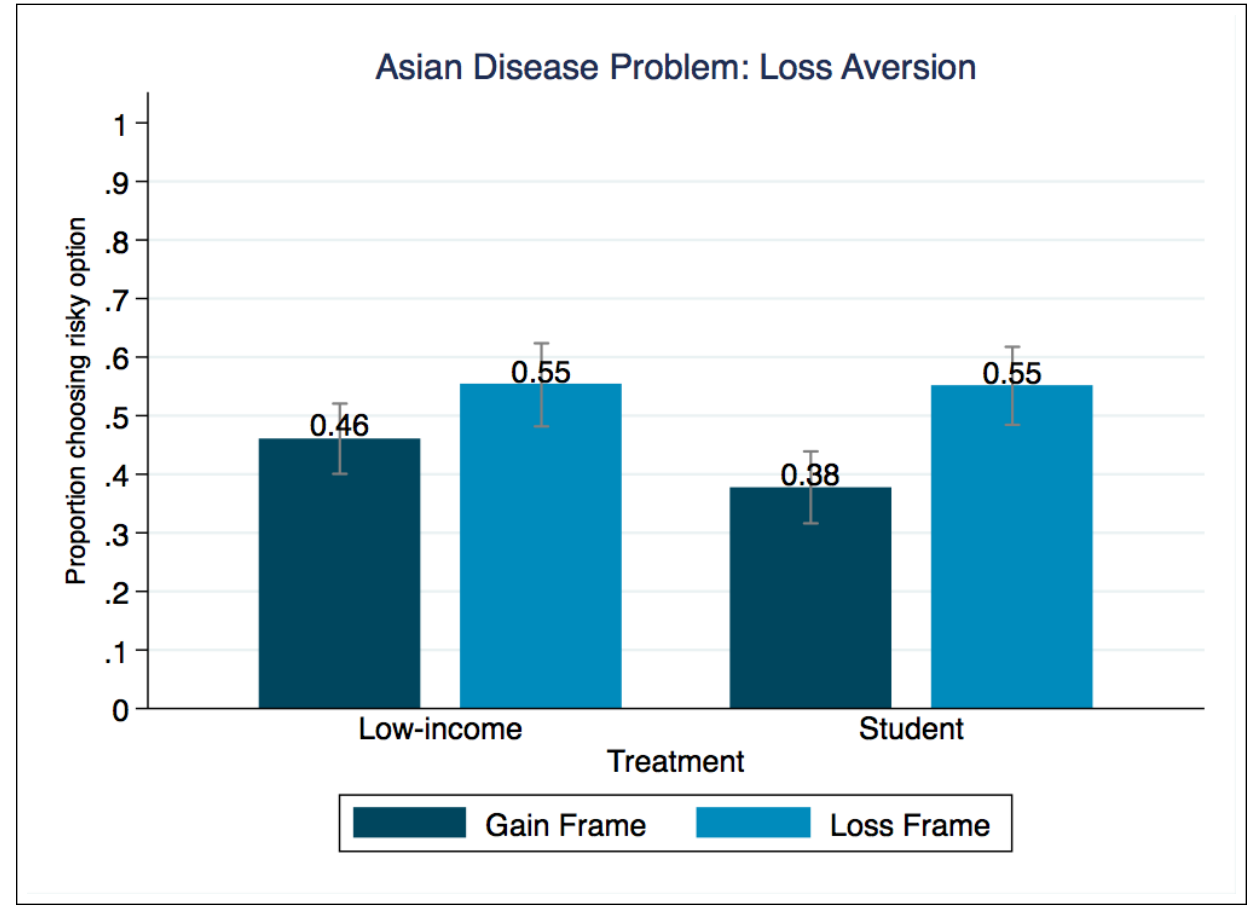

Bars represent the proportion choosing the riskier option

Figure A4: Defaults - Assessment

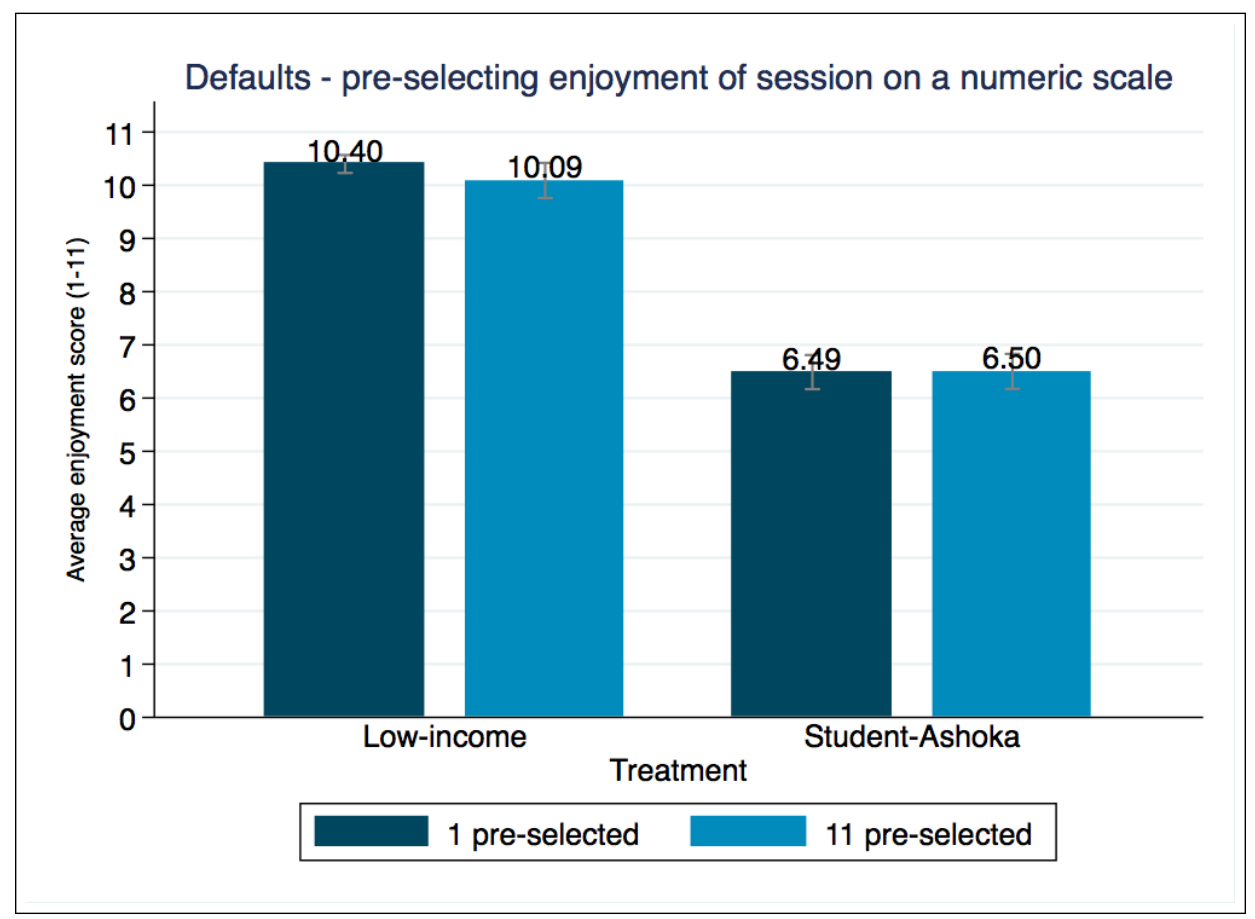

Bars represent the average assessment score for enjoyment of session (out of 11)

\section{Economic Preferences and Decisions}


Figure A5: Anchoring

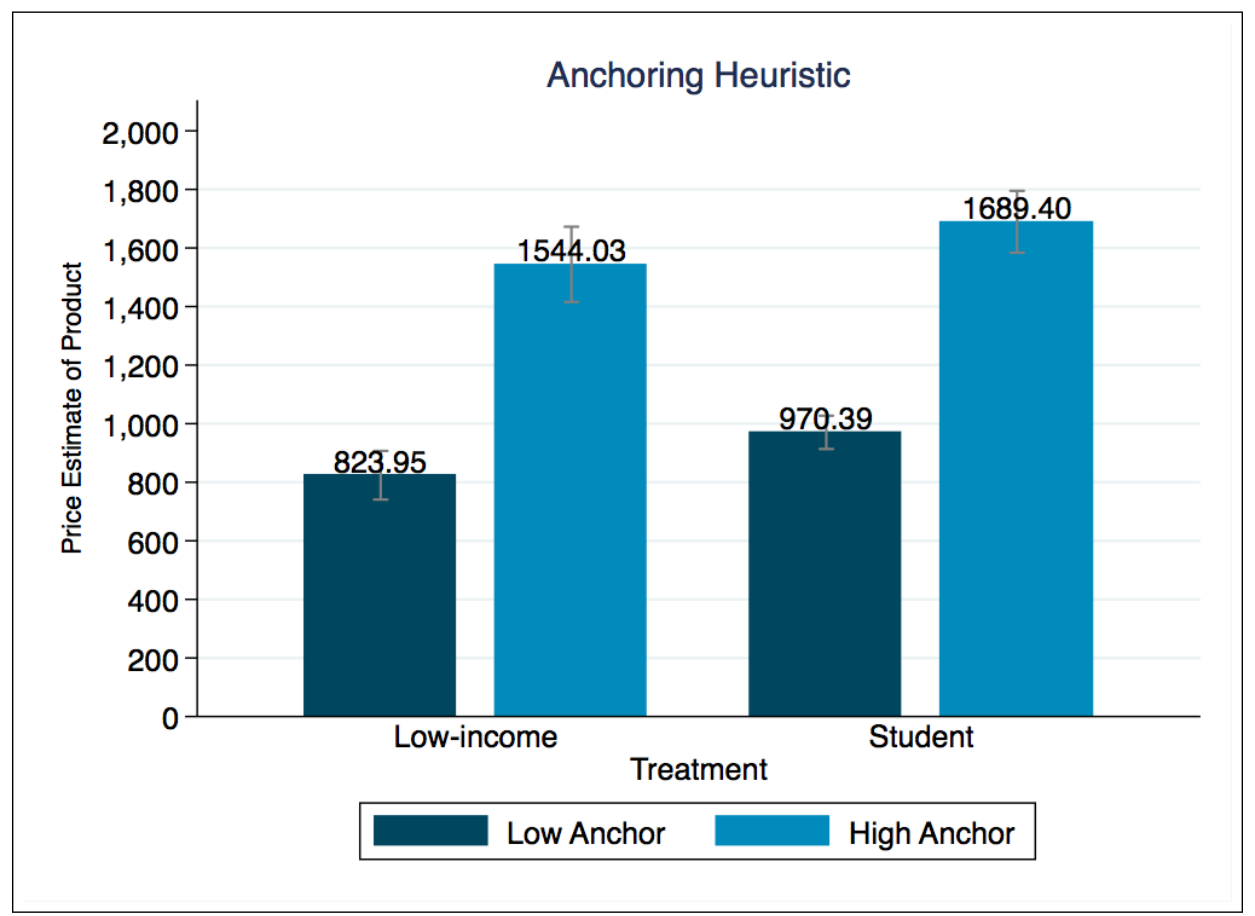

Bars represent the average predicted price of the microplush product

Figure A6: Decoy Effect

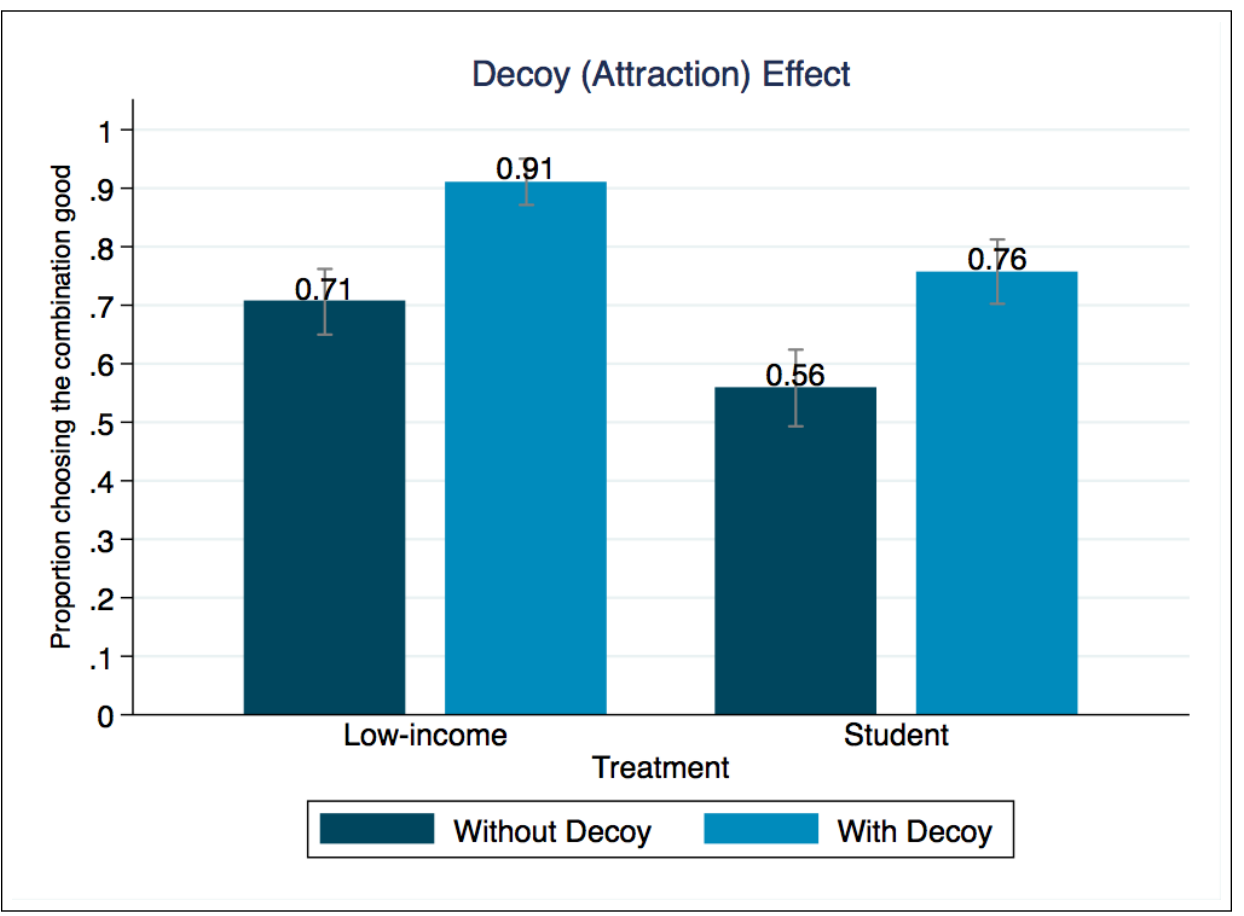

Bars represent the proportion selecting the 'joint good' 
Figure A7: Mental Accounting

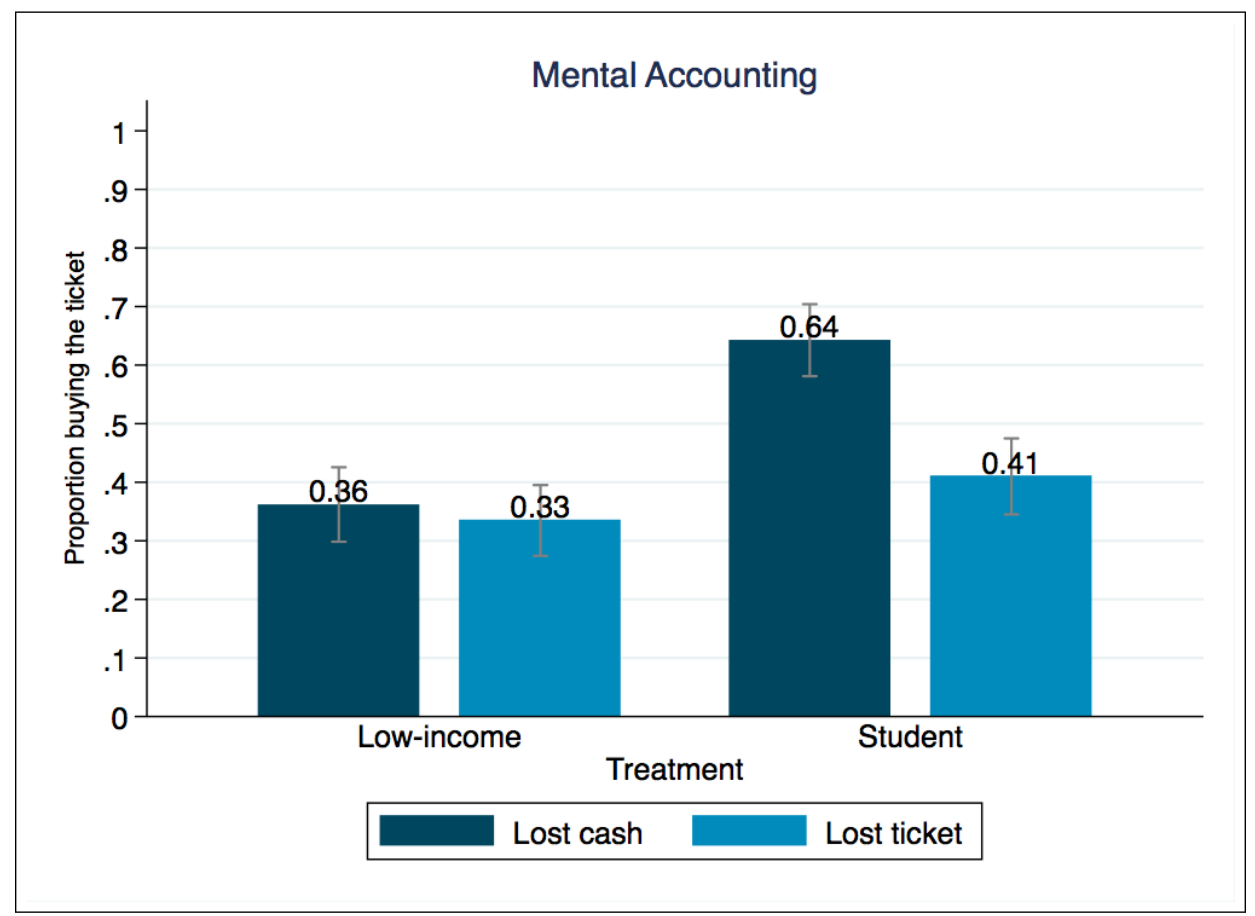

Bars represent the proportion choosing to buy the ticket again

Figure A8: Present Bias

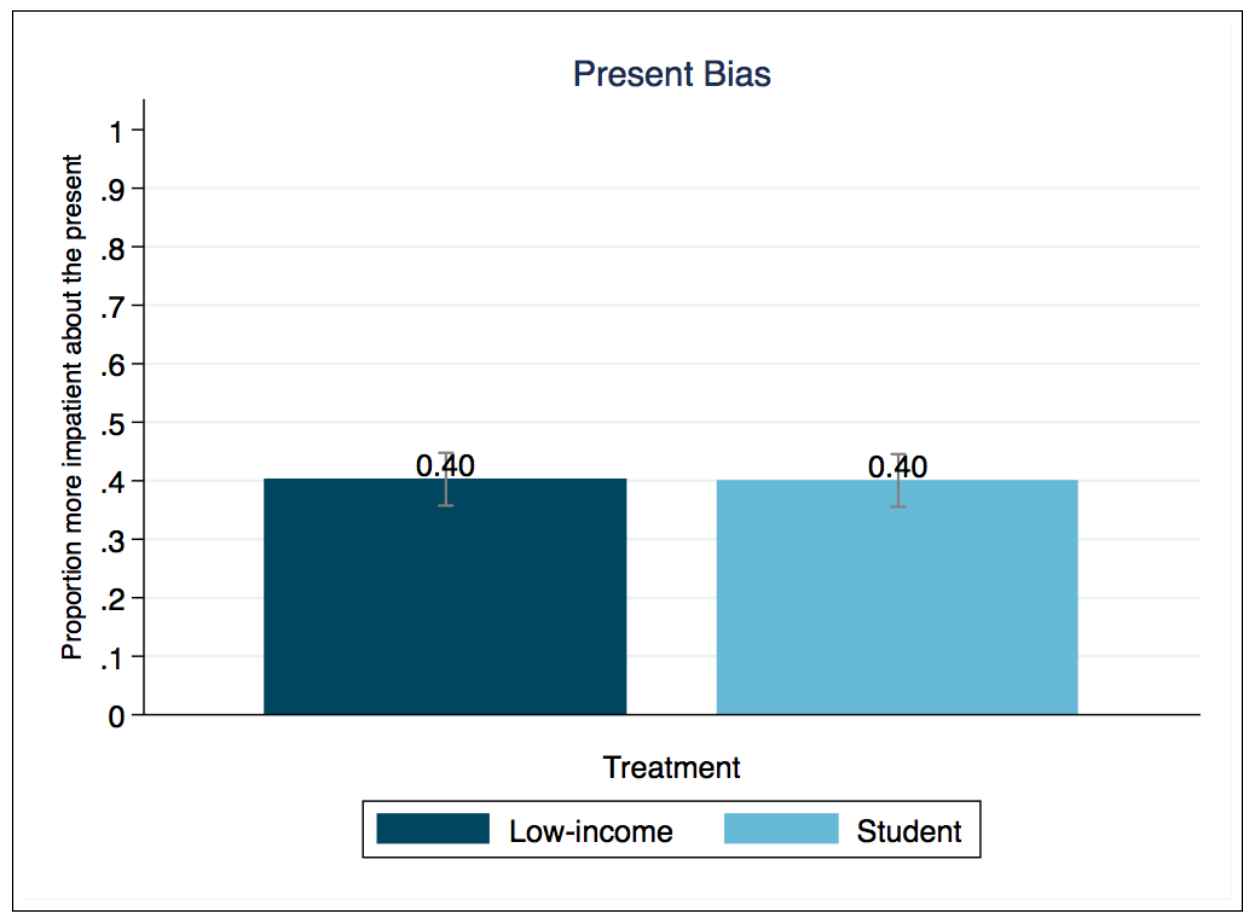

Bars represent the proportion making 'present-biased' choices 
Figure A9: Common Ratio Effect

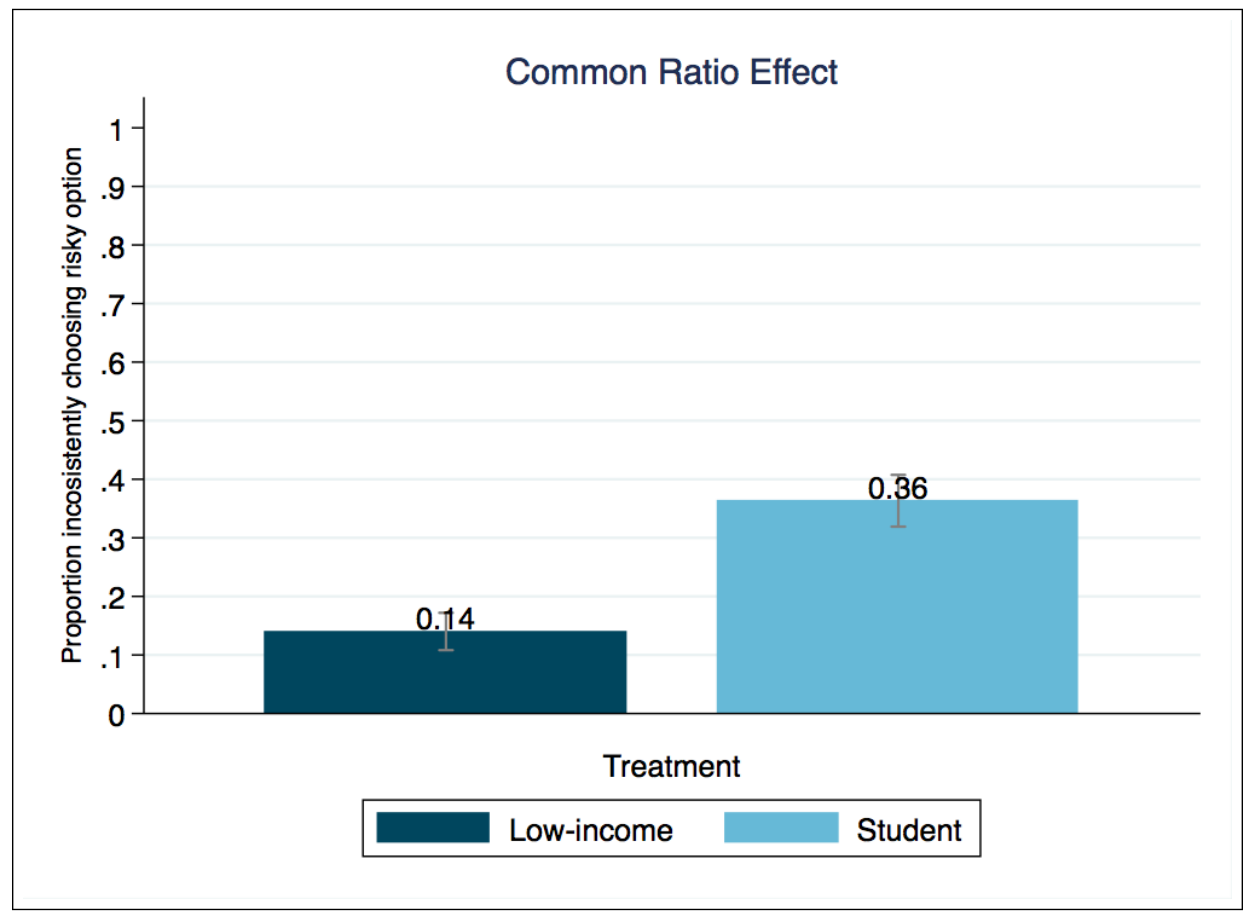

Bars represent the proportion making inconsistent choices in terms of risk preferences and the curvature of their utility function in the selections

Figure A10: Defaults - Charity Selection

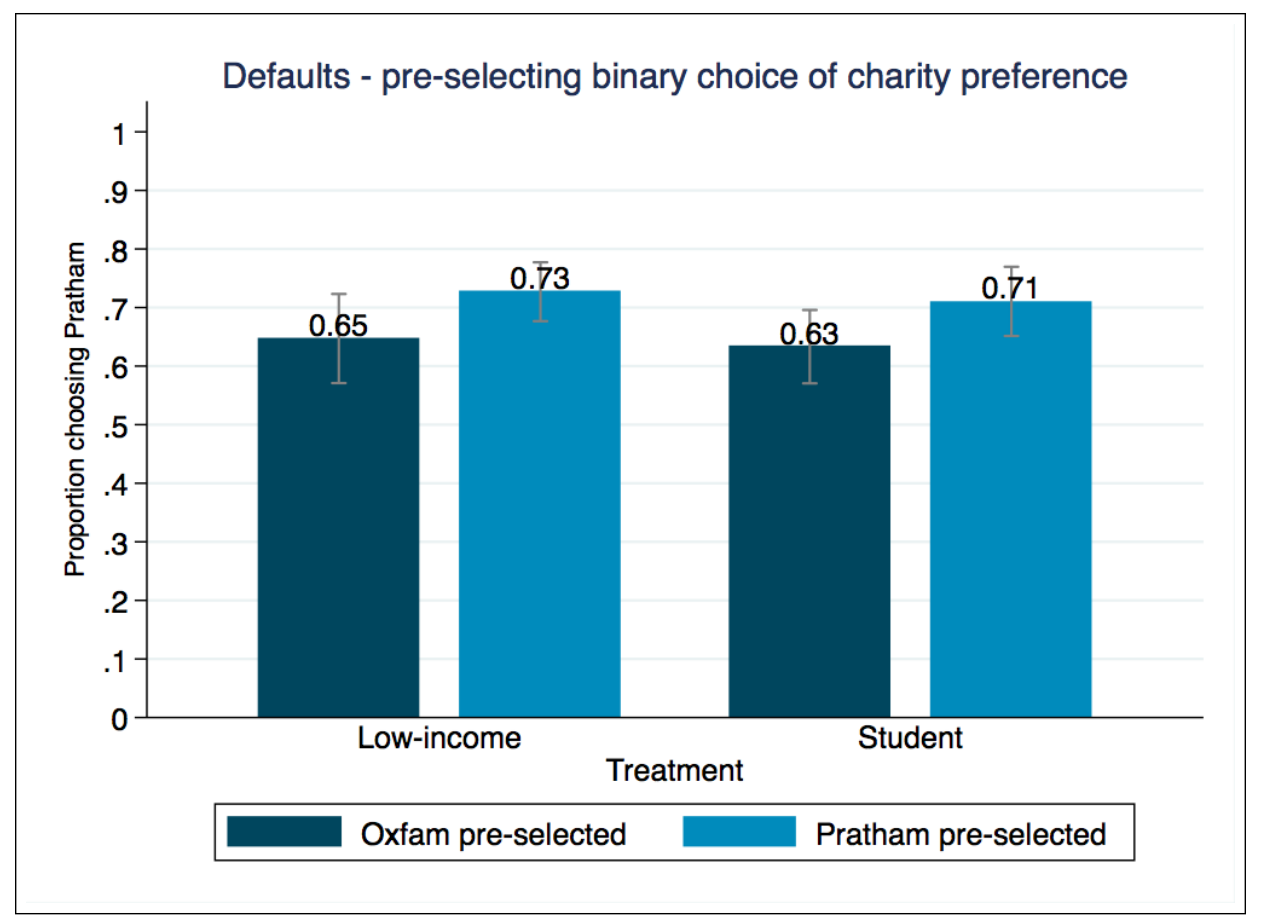

Bars represent the proportion choosing 'Pratham' charity in deciding which charity to donate money to 